\title{
Oxidative stress promotes exit from the stem cell state and spontaneous neuronal differentiation
}

\author{
Qidong Huํㄹ, Puja Khanna ${ }^{1}$, Belinda Shu Ee Wong ${ }^{1}$, Zealyn Shi Lin Heng ${ }^{1}$, Charannya \\ Sozheesvari Subhramanyam ${ }^{1}$, Lal Zo Thanga ${ }^{1}$, Sharon Wui Sing Tan ${ }^{1}$ and Gyeong \\ Hun Baeg ${ }^{1}$ \\ ${ }^{1}$ Department of Anatomy, Yong Loo Lin School of Medicine, National University of Singapore, MD 10, Singapore \\ Correspondence to: Qidong Hu, email: anthq@nus.edu.sg \\ Gyeong Hun Baeg, email: antbgh@nus.edu.sg \\ Keywords: Ntera2 cell; differenitation; reactive oxygen species; oxidative stress
}

Received: September 18, $2017 \quad$ Accepted: December 27, $2017 \quad$ Published: December 30, 2017

Copyright: $\mathrm{Hu}$ et al. This is an open-access article distributed under the terms of the Creative Commons Attribution License 3.0 (CC BY 3.0), which permits unrestricted use, distribution, and reproduction in any medium, provided the original author and source are credited.

\section{ABSTRACT}

Reactive oxygen species (ROS) play important roles in fundamental cellular processes such as proliferation and survival. Here we investigated the effect of oxidative stress on stem cell maintenance and neuronal differentiation in a human embryonic stem cell (hESC) model, Ntera2 (NT2). CM-H2DCFDA and DHE assays confirmed that the oxidizing agent paraquat could induce a high level of ROS in NT2 cells. Quantitative PCR, Western blotting and immunocytochemistry showed that paraquat-induced oxidative stress suppressed the expression of stemness markers, including NANOG, OCT4 and TDGF1, whereas it enhanced the spontaneous expression of neuronal differentiation markers such as PAX6, NEUROD1, HOXA1, NCAM, GFRA1 and TUJ1. The treated cells even exhibited a strikingly different morphology from control cells, extending out long neurite-like processes. The neurogenic effect of ROS on stem cell behaviour was confirmed by the observations that the expression of neuronal markers in the paraquat-treated cells was suppressed by an antioxidant while further enhanced by knocking down Nrf2, a key transcription factor associated with antioxidant signaling. Lastly, paraquat dose-dependently activated the neurogenic MAPK-ERK1/2, which can be reversed by the MEK1/2 inhibitor SL327. Our study suggests that excessive intracellular ROS can trigger the exit from stem cell state and promote the neuronal differentiation of hESCs, and that MAPK-ERK1/2 signaling may play a proactive role in the ROS-induced neuronal differentiation of hESCs.

\section{INTRODUCTION}

Reactive oxygen species (ROS), including superoxide (O-), hydroxyl free radicals $(\mathrm{HO} \bullet)$ and hydrogen peroxide $\left(\mathrm{H}_{2} \mathrm{O}_{2}\right)$, are constantly generated as the result of normal cellular metabolism. In mammalian cells, ROS are mainly generated by membrane-bound NADPH oxidase (NOX) complexes, mitochondria and endoplasmic reticulum [1-4]. Low-to-moderate steadystate levels of ROS are known to be essential for cellular proliferation, differentiation, and survival [5]. However, increased intracellular ROS levels can result in oxidative stress, and cause cellular dysfunctions that lead to accelerated ageing and various human diseases [6, 7]. Hence, it is essential to maintain the redox homeostasis by balancing ROS generation and scavenging systems. The Keap1 (Kelch-like ECH-associated protein 1)/Nrf2 (nuclear factor E2-related factor 2) complex serves as a key sensor of oxidative stress. Nrf2 is a transcription factor that controls the expression of a large pool of antioxidant and detoxifying genes in response to oxidative stress [8]. It is negatively regulated by its physical association with the repressor Keap1 in cytoplasm [9]. However, upon stimulation by oxidative stress, Keap1 becomes inactivated, hence allowing Nrf2 to translocate into nucleus. Nrf2 then engages in the transcriptional 
regulation of many antioxidant and detoxification genes, which are involved in the cellular response to oxidative and electrophilic stress, via antioxidant response element (ARE) [8, 10]. The antioxidant enzymes, such as superoxide dismutase (SOD), catalase, glutathione peroxidase $(\mathrm{GPx})$ and peroxiredoxin (Prx), participate in various enzymatic reactions to convert $\mathrm{O}-$ to $\mathrm{H}_{2} \mathrm{O}$ and dioxide $\left(\mathrm{O}_{2}\right)$ [11-13].

Interestingly, a number of studies, most of which focused on hematopoietic stem cells (HSCs), have shown that redox homeostasis is critical in maintaining the selfrenewal capacity of mammalian stem cells [12, 14, 15]. For example, low level of ROS in stem cell niches is of importance to maintain the stem cell identity of HSCs [16]. When stem cells are exposed to oxidative stress by the disruption of redox homeostasis, they undergo the process of senescence or apoptosis [17]. Similarly, the differentiation of human adipose tissue-derived multipotent adult stem cells toward a neural phenotype was promoted by an increase in ROS [18]. Furthermore, murine ESCs were also known to maintain their stemness and pluripotency under physiological oxygen levels (2\%), but when exposed to prolonged ROS they underwent apoptosis, suggesting the critical role of redox homeostasis in stem cell maintenance $[19,20]$.

Although redox homeostasis has been implicated in the maintenance of stem cells, the molecular regulators of redox homeostasis within stem cells and the ROSmediated effectors of stem cell behaviour remain largely unexplored. In addition, only a few studies have examined the function of ROS in hESCs. Therefore, establishing a reliable and easy-to-use cellular model for the functional studies of ROS may help gain valuable insights into how hESC fate is determined by redox homeostasis and lead to the development of strategies to manipulate hESC ex vivo. Human embryonal carcinoma (hEC) NT2 cells closely resemble hESCs in terms of their pluripotency. When they are injected into immune-deficient mice, they can form teratoma with three primary germ layers [21]. NT2 cells also highly express master regulators such as NANOG (Nanog homeobox), OCT4 (octamer-binding transcription factor 4), SOX2 (SRY-box 2) and TDGF1 (teratocarcinoma-derived growth factor 1), which were previously identified in hESCs [21, 22]. Hence, they have been extensively used to dissect the differentiation of hESCs, especially the all-trans retinoic acid (atRA)induced neuronal commitment [23]. In this study, we attempted to assess whether elevated ROS level and subsequent redox signaling can instruct the differentiation of NT2 cells into neuronal cells. We showed that oxidative stress suppresses the expression of stemness genes but conversely enhances the spontaneous expression of neuronal marker genes. Importantly, the increase in neuronal markers was attenuated by the treatment of cells with an antioxidant. Lastly, our study implicated MAPK-
ERK1/2 in the ROS-mediated neuronal differentiation of NT2 cells.

\section{RESULTS}

\section{Treatment of NT2 cells with paraquat causes an increase in ROS level}

To elucidate the potential role of redox homeostasis in the fate selection of hESCs, we first examined whether the oxidizing agent paraquat can induce oxidative stress in the model cell line NT2 cells. The cells were treated with paraquat at various concentrations for 24 and 40 hours, respectively, and an intracellular ROS level was measured using chloromethyl-H2DCFDA fluorescent probe. At both the time points, the addition of paraquat induced a dose-dependent increase in ROS level (Figure 1A). This was further confirmed by monitoring ROS level using flow cytometry (Figure 1B). DHE is a specific fluorescent probe that detects superoxide radicals. Once oxidized it is intercalated into DNA and generates a red fluorescence. In paraquat-treated NT2 cells, most of them showed red staining in their nuclei, whereas non-treated cells were mostly unlabeled (Figure 1C). All these findings suggest that treatment with oxidizing agents induce oxidative stress in NT2 cells.

\section{A high level of ROS decreases the expression of stemness-related genes}

A low level of ROS has been shown to be essential to maintain the stemness and pluripotency of mammalian ESCs $[19,20]$. This prompted us to test the hypothesis that an elevated level of ROS conversely promotes the exit of NT2 cells from the stem cell state. We first examined the expression of classic ESC markers, including NANOG, OCT4 and TDGF1, in NT2 cells. As expected, Western blotting showed an abundant expression of those stemness markers in control NT2 cells. However, paraquat dosedependently reduced their protein levels, especially at the higher concentrations tested, $75 \mu \mathrm{M}$ and $100 \mu \mathrm{M}$ (Figure 2A). This dose-dependent effect of paraquat on stemness gene expression was further confirmed by quantitative PCR (qPCR) in which higher doses of paraquat (75 and $100 \mu \mathrm{M}$ ) almost completely suppressed the mRNA expression (Figure 2B). However, when cells were treated with another oxidizing agent, hydrogen peroxide $\left(\mathrm{H}_{2} \mathrm{O}_{2}\right)$, the transcript levels of stemness factors remained largely unaltered as determined by qPCR, except Oct4 showing a moderate decrease in cells exposed to a higher dose of $\mathrm{H}_{2} \mathrm{O}_{2}$ (Figure 2C).

Consistently, immunocytochemical analysis showed a dramatic decrease in the fluorescence intensity of these stemness markers in paraquat-treated cells (Figure 2D), suggesting that NT2 cells under oxidative stress lose their stemness. In alignment with the qPCR data, $\mathrm{H}_{2} \mathrm{O}_{2}$ 
A

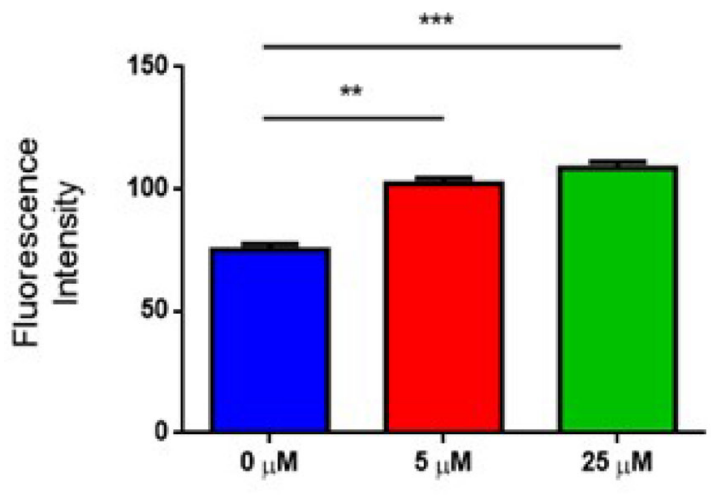

[Paraquat] 24 hours

B

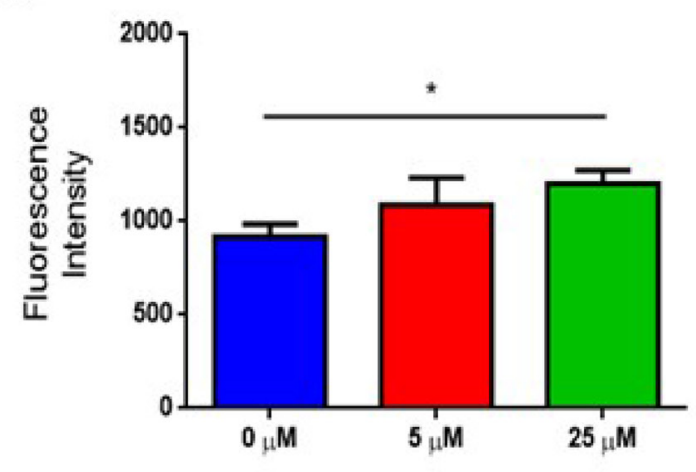

[Paraquat] 40 hours

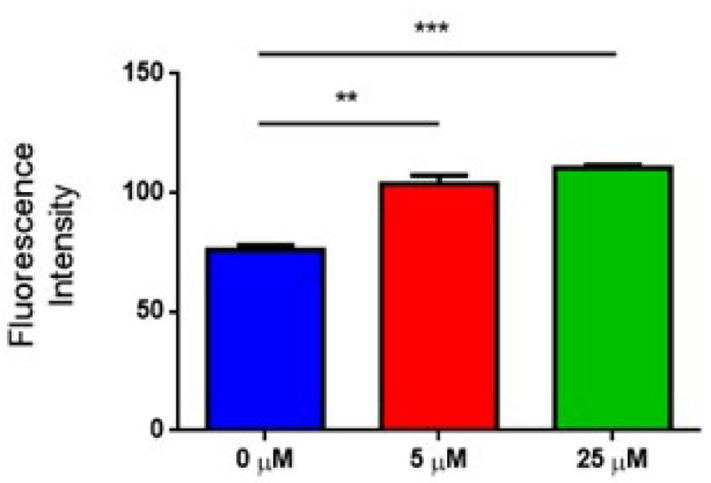

[Paraquat] 40 hours

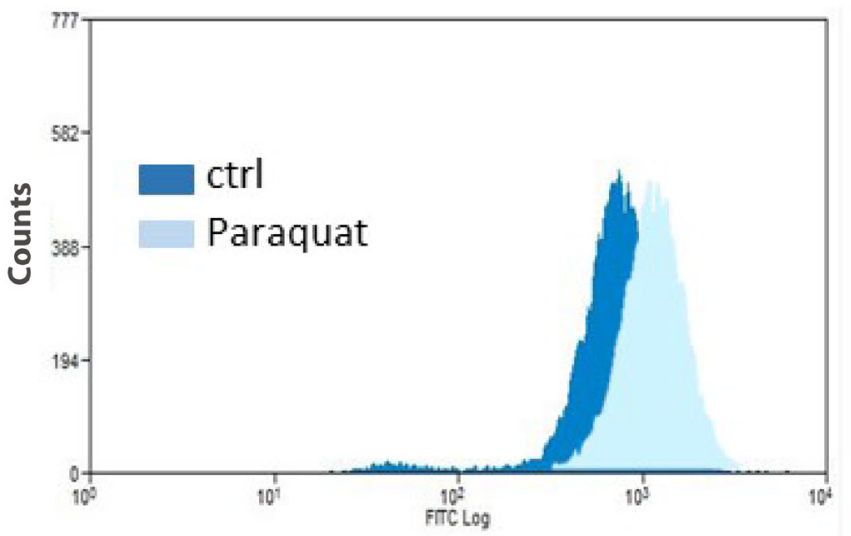

C

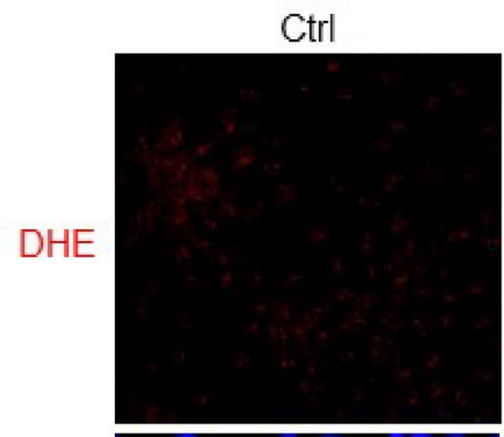

Paraquat
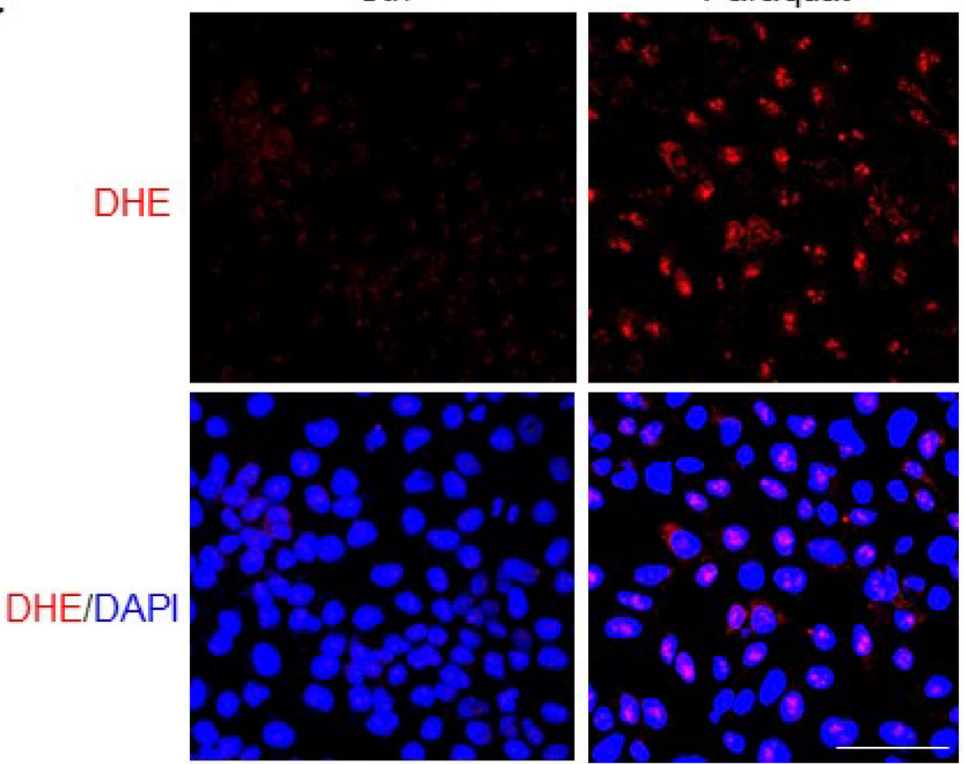

Figure 1: Paraquat increases ROS level in NT2 cells. (A) Cells were treated with paraquat at the indicated concentrations for 24 hours (left panel) and 40 hours (right panel). Chloromethyl-H2DCFDA dye was used to measure ROS level using spectrometry. Bar: mean \pm SEM; ${ }^{* *} p<0.01,{ }^{* * *} p<0.001$. (B) Cells were treated with paraquat for 40 hours. ROS level was assessed by staining with chloromethylH2DCFDA, and fluorescence intensity was monitored by flow cytometry. Bar: mean \pm SEM; ${ }^{*} p<0.05$. (C) Cells treated with $25 \mu \mathrm{M}$ paraquat were stained with dihydroethidium (DHE) to visualize the induction of ROS. Scale bar: $100 \mu \mathrm{m}$. 
A

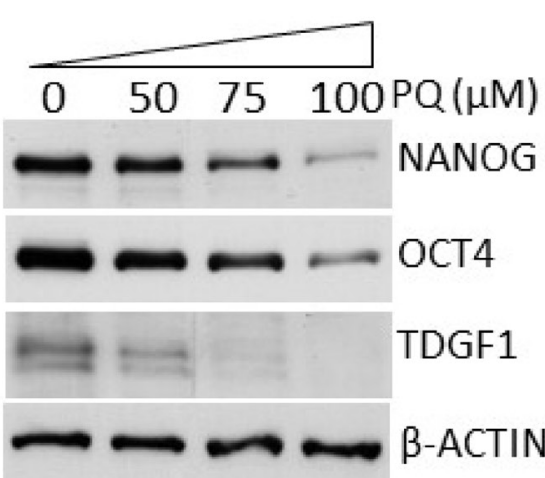

C

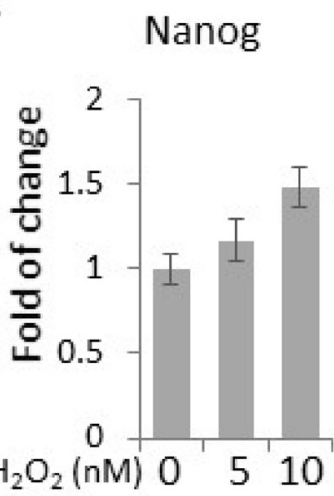

Oct4

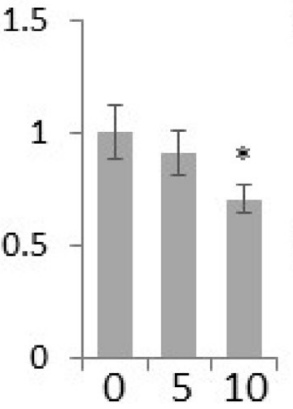

Tdgf1

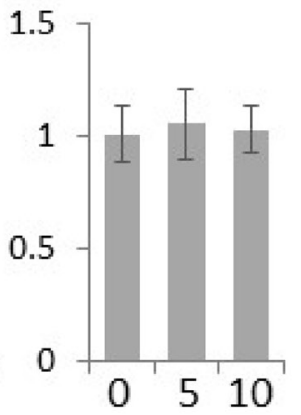

B

Nanog

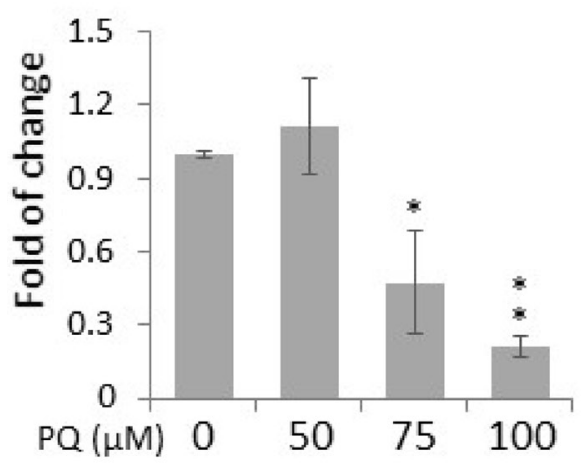

D
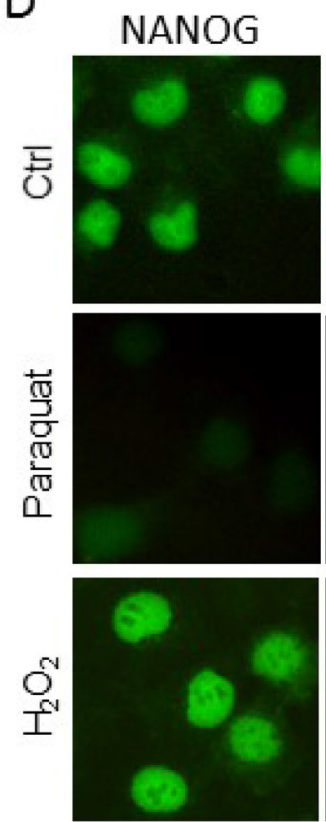

Merge
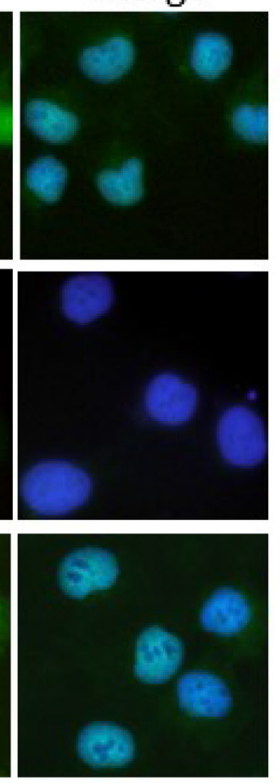

Oct4
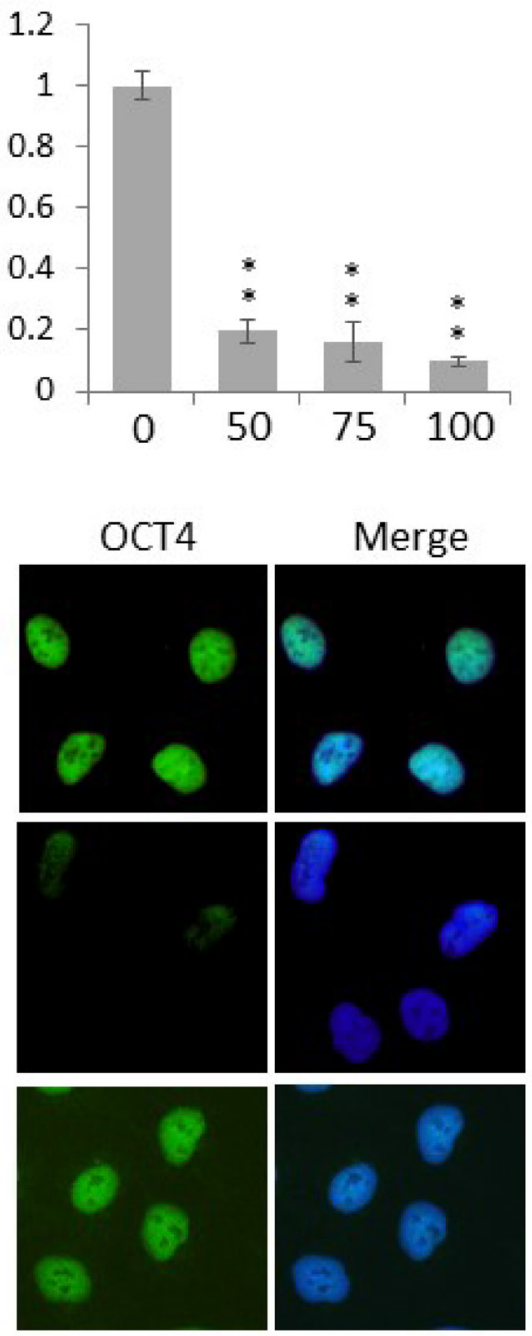

Tdgf1
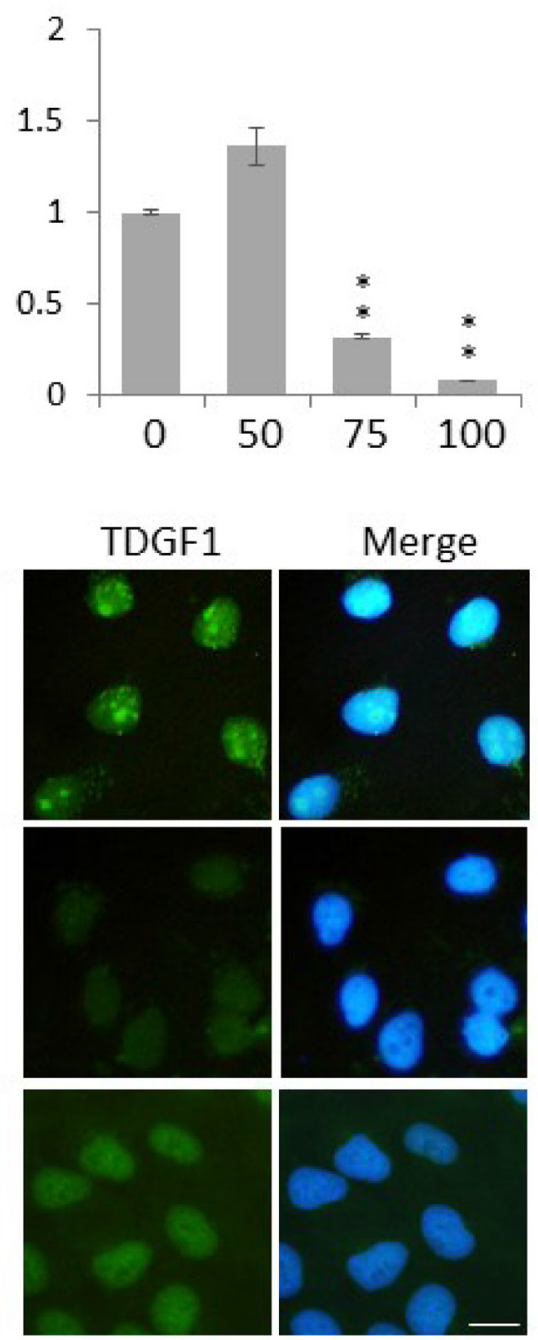

Figure 2: Enhanced ROS decrease the expression of stemness genes in NT2 cells. (A) Cells treated with paraquat (PQ) at the indicated concentrations were lyzed, and the protein levels of stemness markers, NANOG, OCT4 and TDGF1, were examined by Western blot. $\beta$-ACTIN was used as the loading control. Cells treated with indicated concentrations of PQ (B) or $\mathrm{H}_{2} \mathrm{O}_{2}(\mathbf{C})$ for two days were lyzed for total RNAs. The transcript levels of stemness genes were measured by qPCR. Bar: mean $\pm \mathrm{SD} ;{ }^{*} p<0.05,{ }^{* *} p<0.01$ by Student $t$-test. (D) Cells were treated with $50 \mu \mathrm{M}$ paraquat or $10 \mathrm{nM} \mathrm{H}_{2} \mathrm{O}_{2}$ for six days and immunostained for the above stemness markers. The cells were counterstained with DAPI. Scale bar: $20 \mu \mathrm{m}$. 
treatment did not lead to a pronounced decrease in the immunolabeling of NANOG, OCT4 or TDGF1 (Figure 2D), suggesting that it is less potent than paraquat in reducing stemness.

\section{A high level of ROS enhances the expression of neuronal differentiation markers}

The differentiation of human adipose tissue-derived multipotent adult stem cells towards a neural phenotype was shown to be accompanied by an increase in ROS levels [18]. Hence, we proceeded to examine whether the paraquat-induced elevation of ROS levels can spontaneously initiate the neuronal differentiation of NT2 cells. First, to verify the neurogenic potential of NT2 cells, we treated the cells with the well-established neurogenic agent, atRA [24]. qPCR showed that atRA could potently induce the expression of a panel of neurogenic genes, including Pax6 (Paired box 6) [25], Gfral (GDNF family receptor alpha 1) [26], Hoxal (Homeobox A1) [27], Ncam (Neural cell adhesion molecule 1) [28] and Neurod1 (Neuronal differentiation 1) [29], as well as Cyp26a1 (Cytochrome P450 family 26 subfamily A member 1), an important feedback factor of atRA signaling in both hESCs and NT2 [30, 31] (Figure 3). For comparison, the cells were then treated with paraquat for different durations. Remarkably, at all the three concentrations tested, $5 \mu \mathrm{M}, 25 \mu \mathrm{M}$ and $100 \mu \mathrm{M}$, the expression of these canonical differentiation markers was increased in a timedependent manners (Figure 4A), suggesting that oxidative stress alone can initiate the neuronal differentiation of NT2 cells. Surprisingly, in response to paraquat, we noticed a time-dependent reduction in the transcript level of Cyp26al (Figure 4A). Since CYP26A1 is a negative regulator of the neurogenic atRA signaling cascade $[30,31]$, its suppression may render a more permissive environment for the ROS-induced neuronal differentiation of NT2 cells. To further confirm the notion that elevated ROS levels promote neuronal differentiation, we treated NT2 cells with paraquat at different concentrations for 2 days and examined the transcript levels of two neurogenic transcription factors, Pax6 and Neurod1. We found that $20 \mu \mathrm{M}$ paraquat is sufficient to elicit a significant induction of these factors (Figure 4B). Consistently, we also observed a dose-dependent decrease in Cyp26al expression by paraquat treatment (Figure 4B), suggesting a potential cross-talk between oxidative stress signaling and neurogenic atRA signaling.

Intriguingly, although $\mathrm{H}_{2} \mathrm{O}_{2}$ did not suppress the expression of stemness genes as efficiently as paraquat (Figure 2C, 2D), it could significantly elevate the transcript levels of neuronal genes in a dose-dependent manner (Figure 4C), implying that increased ROS levels could play an important role in maintaining a delicate balance between stemness and differentiation.

\section{High ROS induce the outgrowth of neurite-like processes in NT2 cells}

One of the striking features of neuronal differentiation is the neurite outgrowth, a projection of axons and dendrites [26, 32]. Since paraquat treatment enhanced the expression of neuronal markers (Figure 4A, 4B), we further assessed whether oxidative stress can induce a morphological change in NT2 cells. After treatment with $25 \mu \mathrm{M}$ paraquat for six days, the cells were immunostained for NEUROD1 and TUJ1 (Tubulin beta 3 class III), a neuron-specific tubulin protein [33]. Consistent with the notion that oxidative stress enhances neuronal differentiation, a significant increase in the staining of NEUROD1 and TUJ1 was observed in treated cells. Importantly, some of the treated cells exhibited an expanded cytoplasm and started to extend out cell processes (Figure 5A, arrowhead), indicating that paraquat-induced expression of neuronal markers can be accompanied by alterations in cell morphology. To further relate the observed morphological changes to neurite-like outgrowth, we treated NT2 cells with the higher concentration of paraquat at $100 \mu \mathrm{M}$ for six days. As expected, the treated cells showed a much lower
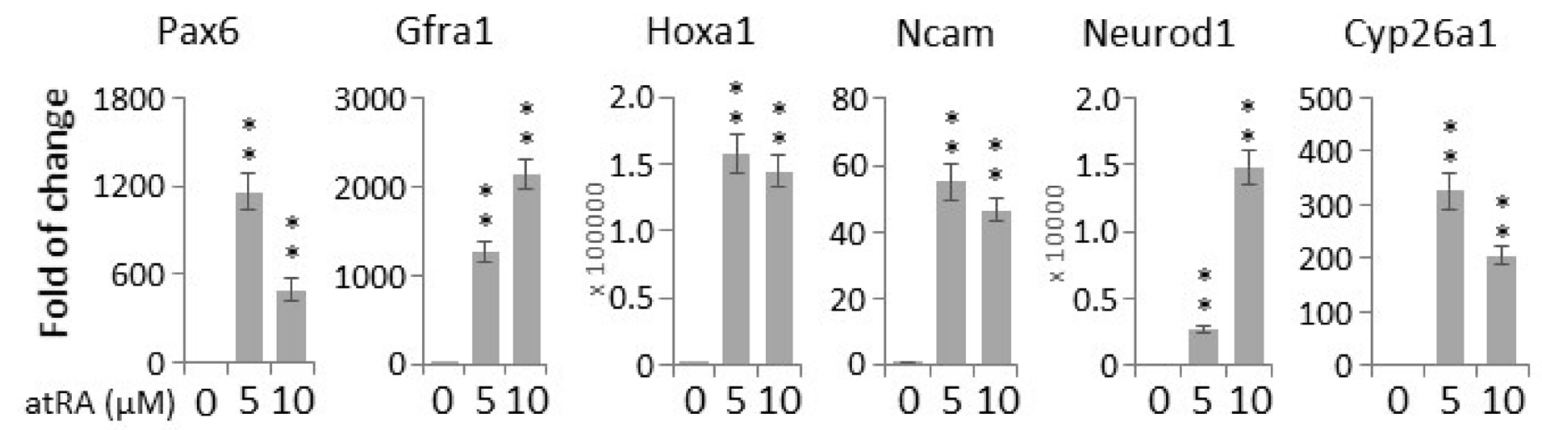

Figure 3: All-trans retinoic acid (atRA) induces neurogenic gene expression in NT2 cells. Cells were treated with indicated concentrations of atRA for two days, and the transcript levels of canonical neuronal genes were determined by qPCR. Bar: mean \pm SD; ${ }^{* *} p<0.01$ by Student $t$-test. 
A

Pax6

Gfra1

Hoxa1
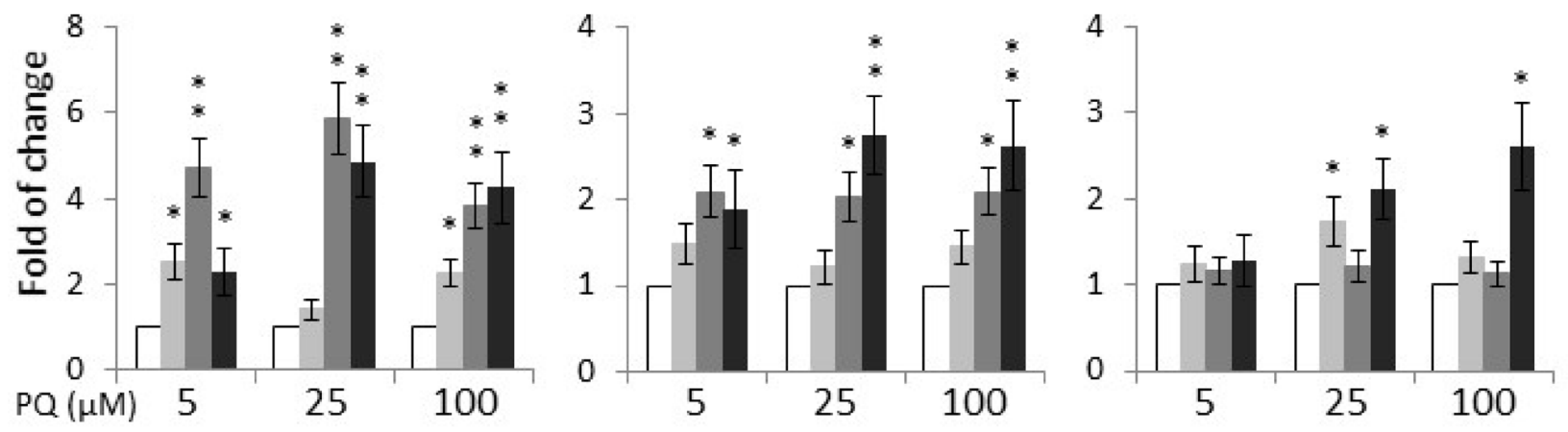

Ncam
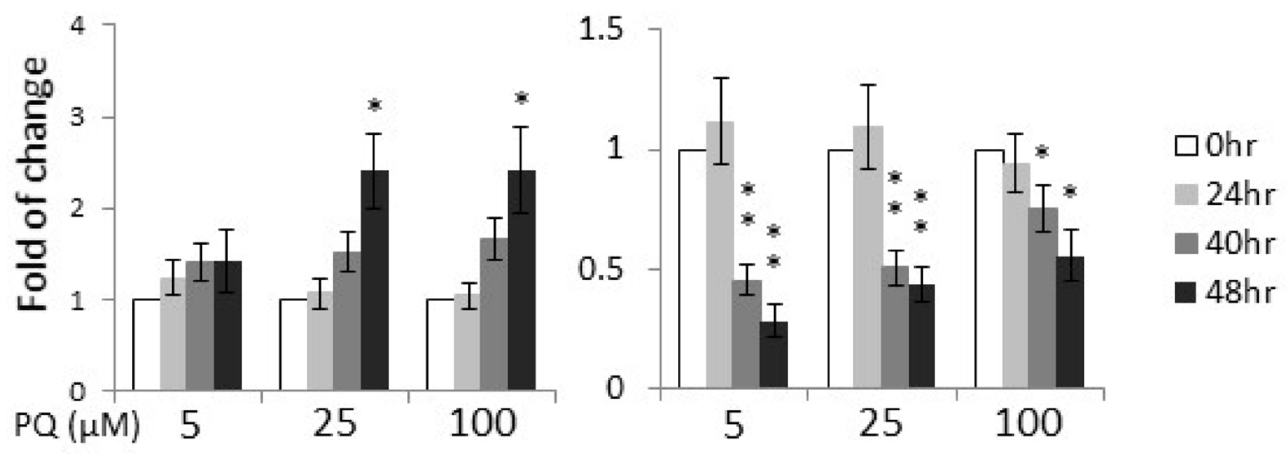

B

Pax6

Neurod1

Сур26а1
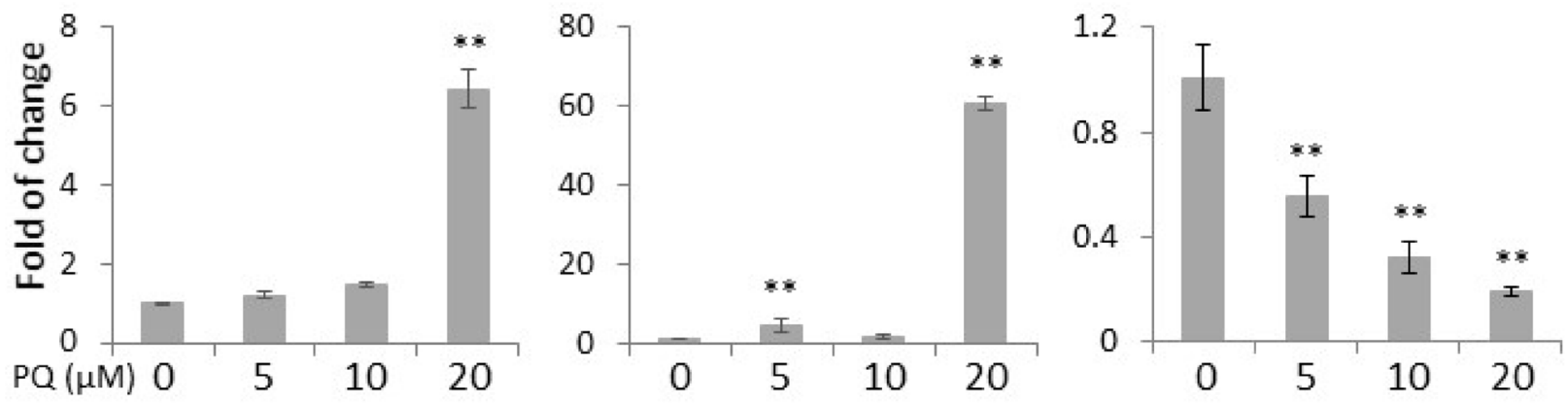

C
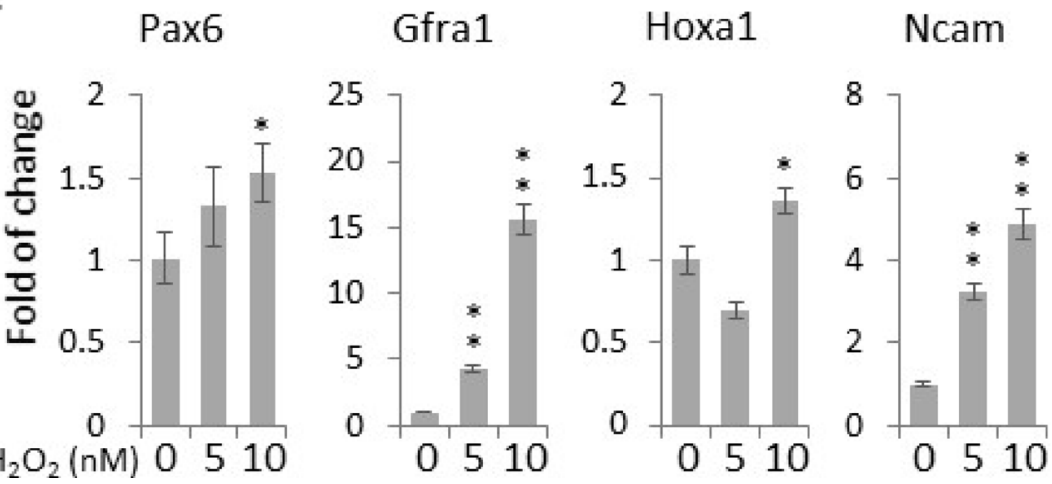

Neurod1

Cyp26a1
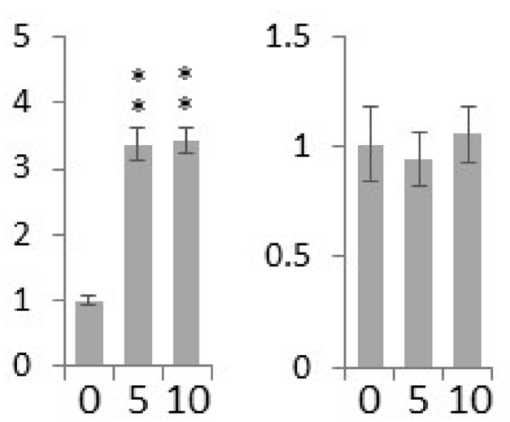

Figure 4: Paraquat induces the expression of neuronal markers in NT2 cells. (A) Cells were treated with paraquat for different durations. qPCR was performed to measure the time-dependent expression of neuronal markers. (B) Cells were treated with indicated concentrations of paraquat for two days. The dose-dependent expression of neuronal transcription factors (Pax6 and NeuroD1) and Cyp26al was quantified by qPCR. (C) Cells were treated with $\mathrm{H}_{2} \mathrm{O}_{2}$ at different concentrations for two days and analysed by qPCR for the transcript levels of neuronal marker genes. Bar: mean $\pm \mathrm{SD} ;{ }^{*} p<0.05,{ }^{* *} p<0.01$ by Student $t$-test. 
A NEUROD1
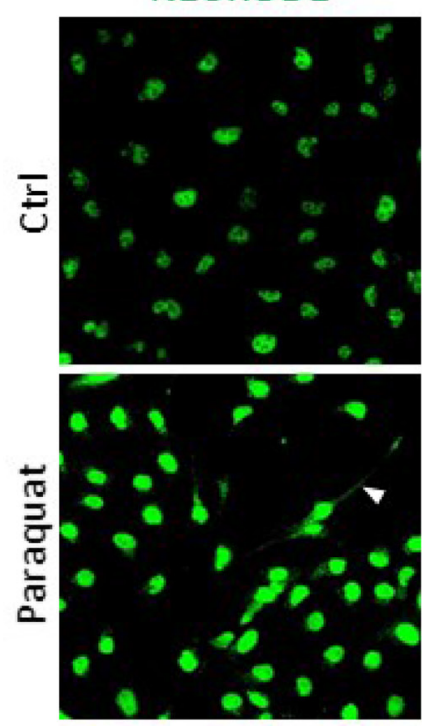

B
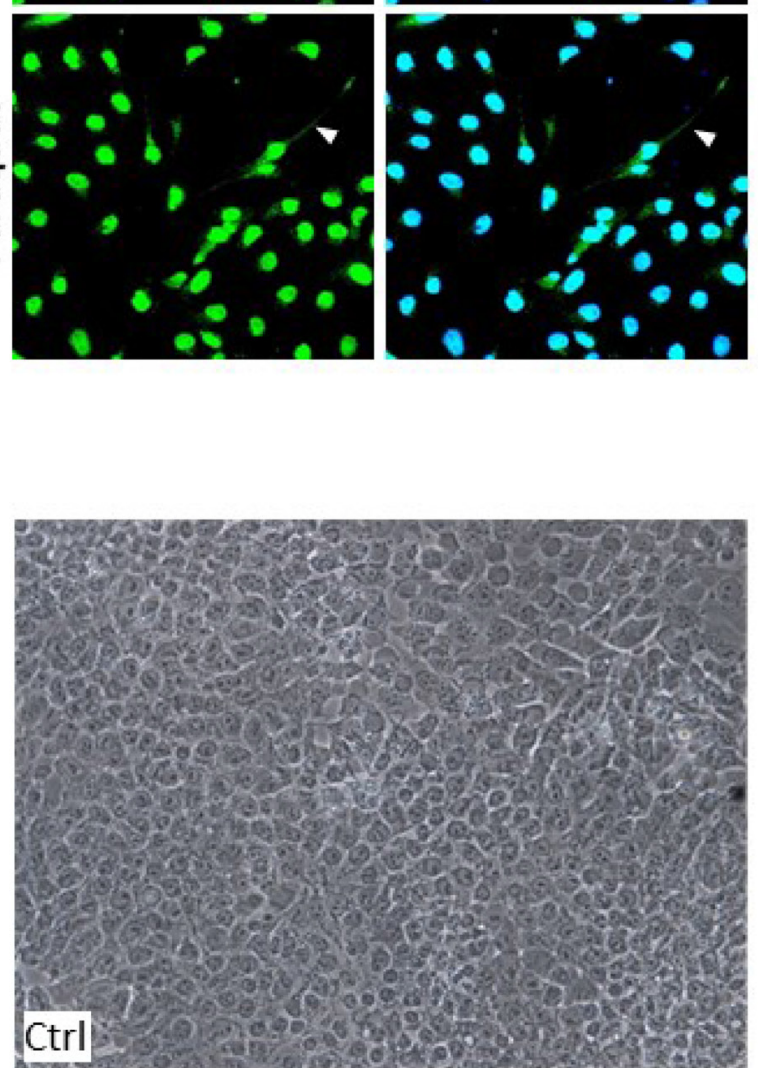

TUJ1
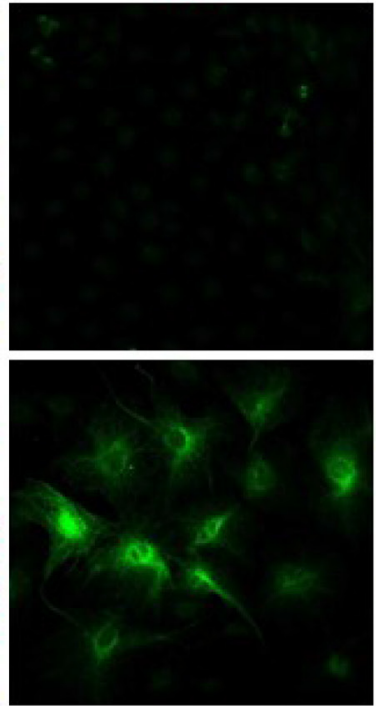

TUJ1/DAPI
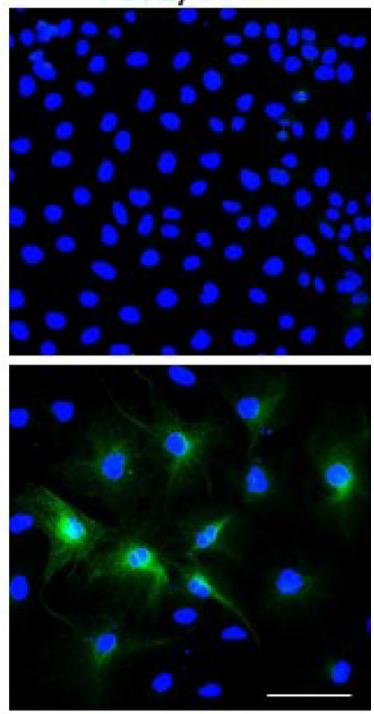

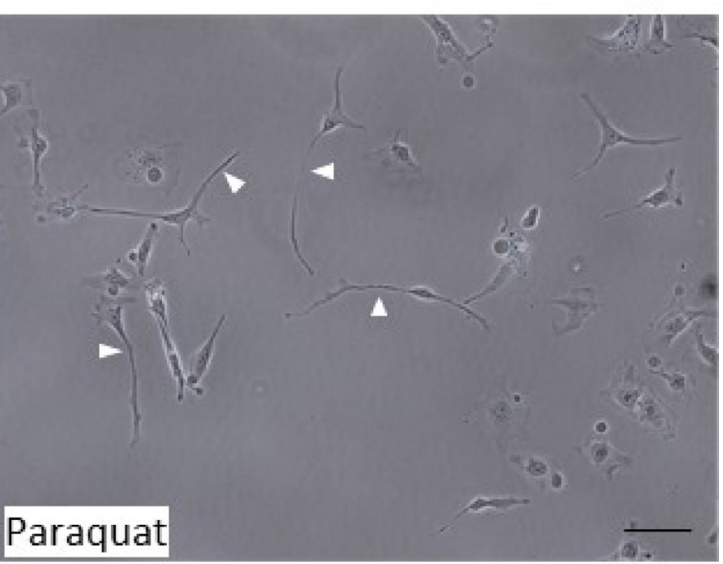

C
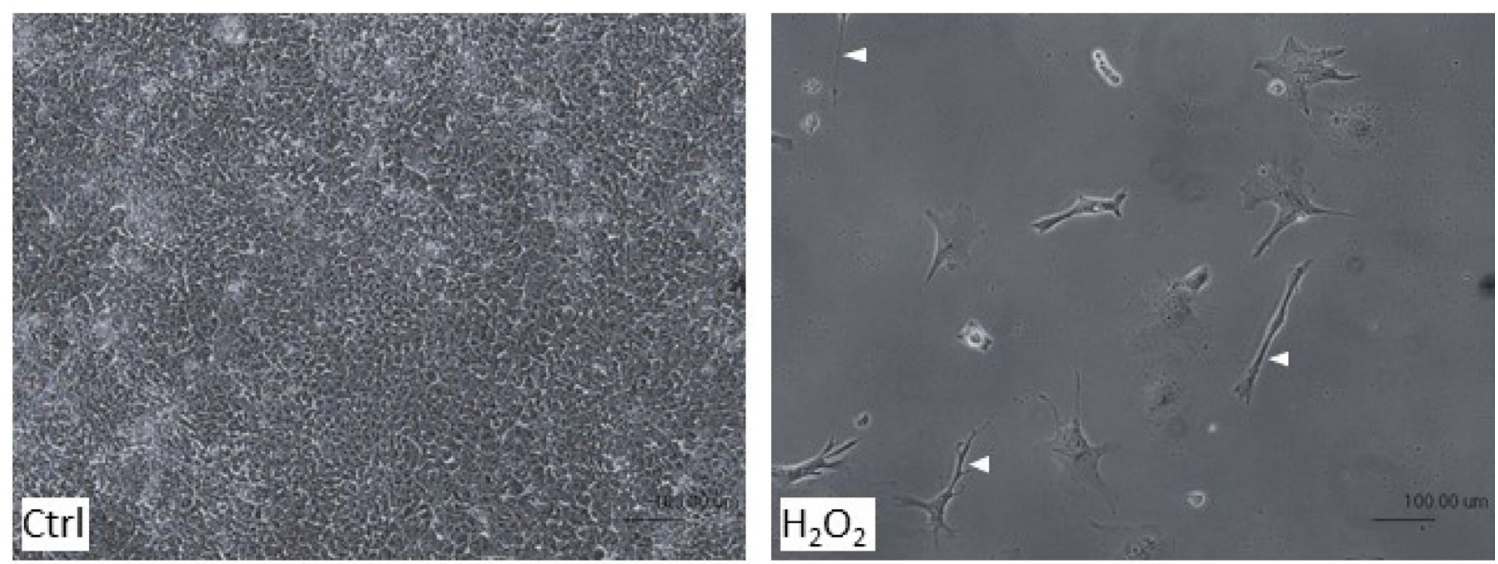

Figure 5: Enhanced ROS cause morphological changes in NT2 cells. (A) Cells were treated with $25 \mu \mathrm{M}$ paraquat for six days and immunostained with neuronal markers, NEUROD1 and TUJ1. The cells were counterstained with DAPI. The arrowhead denotes neurite-like cellular process. (B, C) Cells were treated with $100 \mu \mathrm{M}$ paraquat (B) or $5 \mathrm{nM} \mathrm{H}_{2} \mathrm{O}_{2}$ (C) for six days, and the morphological changes were visualized by phase-contrast microscopy. The arrowheads point to elongated cellular processes. Scale bar: $100 \mu \mathrm{m}$. 
proliferative activity as compared to control cells, and exhibited a striking bipolar extension of cell processes which is reminiscent of the neurite outgrowth (Figure 5B, arrowhead). To examine whether other reactive oxygen species could also induce the neurogenic morphological change, the cells were exposed to $5 \mathrm{nM} \mathrm{H}_{2} \mathrm{O}_{2}$. Remarkably, we observed a significant decrease in cell proliferation but a prominent outgrowth of cell processes (Figure 5C, arrowhead), suggesting that oxidative stress can generally induce neuronal differentiation.

\section{Antioxidant treatment impedes high ROS- mediated neuronal differentiation}

To confirm that the paraquat-induced spontaneous expression of neuronal genes was mediated by oxidative stress, we assessed whether the concurrent treatment of NT2 cells with the antioxidant glutathione (GSH) can antagonize the neurogenic effect of paraquat. Interestingly, we observed that GSH significantly reduces the paraquatinduced expression of neuronal differentiation markers, including Neurod1, Ncam and Gfral (Figure 6A). To test whether an elevated level of ROS is a common cause of neuronal differentiation in stem cells, we next examined the effect of GSH on atRA-mediated neuronal differentiation by co-treating NT2 cells with GSH and atRA, a well-established neurogenic agent. Remarkably, the addition of GSH in part attenuated the effects of atRA on the expression of neuronal makers (Figure 6B), suggesting that ROS also play important roles in atRAinduced neuronal differentiation of NT2 cells.

\section{Paraquat-induced ROS influence antioxidant signaling}

The Keap1/Nrf2 pathway plays a major role in maintaining the redox homeostasis. In a physiological condition, Keap1 acts as a cytoplasmic repressor of $\mathrm{Nrf} 2$ by binding and promoting its degradation $[8,9]$. However, upon oxidative stress, Nrf2 is released from Keap1, translocates into nucleus and engages in the transcriptional activation of various antioxidant and detoxifying genes. In support of this, we found that paraquat treatment increases the expression of $\mathrm{Nrf2}$ but had no significant effect on Keapl expression in NT2 cells (Figure 7A), suggesting a feedback loop to regulate redox balance. PRDM16 (PR domain 16) is also an important antioxidant protein that functions in regulating an intracellular ROS level and thus maintains redox homeostasis [34]. Importantly, it has been shown that the addition of the antioxidant N-acetylcysteine to Prdm16-deficient mice partially rescues defects in neural stem cell function, suggesting that PRDM16 facilitates neural stem cell maintenance by modulating oxidative stress [34]. With qPCR, we observed a dosedependent increase in $\operatorname{Prdm} 16$ expression by paraquat treatment similar to that in $\mathrm{Nrf2}$ (Figure 7A). However, co-treatment of the cells with GSH significantly decreased Prdm16 expression induced by paraquat, suggesting an intricate PRDM16-modulated feedback loop to regulate redox homeostasis.

Since elevated ROS promote neuronal differentiation, we next examined whether the disruption of the antioxidative Nrf2 pathway can further enhance the expression of neuronal markers induced by paraquat. As expected, the knockdown of $N r f 2$ in paraquat-treated cells further enhanced the mRNA levels of Nestin, a neural progenitor cell marker [35, 36], Gfral and Hoxal as compared to that in cells treated with paraquat alone (Figure 7B), confirming that a high ROS level facilitates neuronal differentiation via inducing oxidative stress.

\section{MAPK-ERK1/2 is dose-dependently activated by paraquat}

The mitogen-activated protein kinase (MAPK) cascade is an important signaling pathway that has a major role in multiple biological processes such as development, cell proliferation, apoptosis and stress response [37]. There are three main MAPK subfamilies, ERK1/2, JNK and p38. Notably, a number of studies have implicated the activation of MAPKs in the self-renewal and differentiation of neural stem/progenitor cells or ESCs [38-42]. In particular, atRA treatment has been shown to promote phosphorylation of ERK1/2 in murine ESCs [43]. Hence, we examined whether ERK1/2 become activated in the oxidative stress-mediated neuronal differentiation of NT2 cells. Interestingly, immunoblotting showed that phospho-ERK1/2 level increased in a dose-dependent manner in response to paraquat (Figure 8A). However, MEK1/2, upstream kinases of ERK1/2, were not affected by paraquat. Hence, to confirm the essential role of ERK1/2 in paraquat-induced neuronal differentiation, the cells were concurrently treated with paraquat and the specific MEK1/2 inhibitor SL327 [44], which was shown to decrease phospho-ERK1/2 levels very efficiently in NT2 cells (Figure 8B). The phase contrast images showed that the inhibition of ERK1/2 activation by SL327 dramatically restored the paraquat-suppressed cell proliferation and prevented the neurite-like outgrowth from the cells (Figure 8C). Altogether, these observations suggest that paraquat-induced oxidative stress may promote neuronal differentiation of NT2 cells by activating the MAPKERK1/2 signaling pathway.

\section{DISCUSSION}

During the cellular metabolism of oxygen, ROS are constantly produced from NOX complexes in the cell membranes, mitochondria and endoplasmic reticulum [1-4]. However, redox homeostasis is achieved by a delicate balance between the production and the destruction of ROS to ensure the functional integrity of 
cells, including proliferation, differentiation and survival [5]. A significant deviation from the homeostasis may initiate oxidative stress in cells, resulting in physiological changes and pathological features that include accelerated ageing, neurodegeneration and tumorigenesis [6, 7]. Hence, it is critical to explore the effect of oxidative stress in different cellular contexts, and to characterize the molecular mechanism underlying the physiological and pathological changes.

In this study, we used the human EC cell line NT2 as a surrogate to investigate the role of redox homeostasis in regulating the cell fate of hESCs. It has been shown that a low level of ROS is required for the maintenance of stemness in other stem cell models such as murine ESCs, human HSCs and adipose tissue-derived multipotent adult stem cells $[16,18-20]$. Consistently, in NT2 cells, a significant decrease in the expression of some master regulators of stemness, including NANOG, OCT4 and TDGF1, was observed upon oxidative stress induced by paraquat (Figure 2), suggesting that low levels of ROS may be required for hESCs to maintain their stem identity. Our study also provided evidence that paraquat-treated NT2 cells spontaneously express neurogenic transcription factors and neuron-specific structural molecules, including PAX6, NEUROD1, HOXA1, NCAM and TUJ1 (Figure 4A, 4B, 5A). In addition, we observed significant changes in the morphology of the cells, extending out neurite-like cell processes (Figure 5B). These findings are consistent with the previous report, showing that adipose tissuederived adult stem cells exhibit a neural phenotype when experiencing an increase in ROS level [18]. In fact, our preliminary study using the fruit fly Drosophila also showed that redox homeostasis plays important roles in regulating the behaviour of neural stem cells in the developing larval brain (unpublished data).

Surprisingly, the addition of the antioxidant GSH significantly suppressed the expression of neuronal genes induced by the well-known neurogenic agent atRA [33] (Figure 6B), suggesting that redox signaling may be involved in the atRA-induced neuronal differentiation
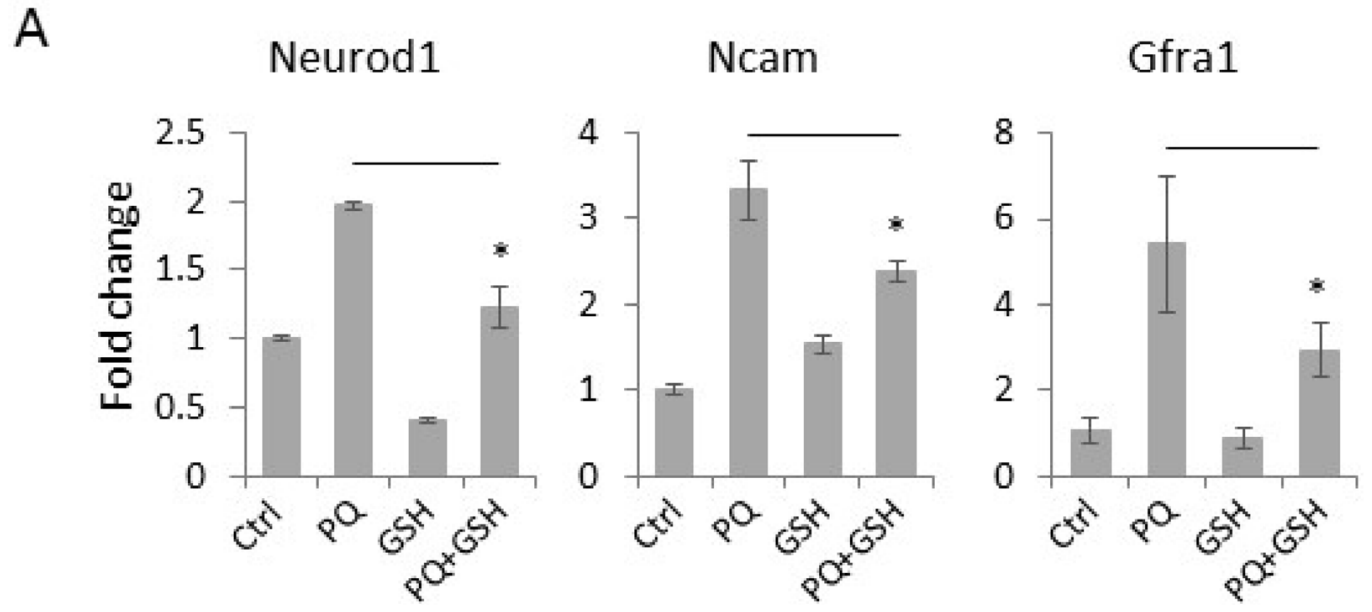

B
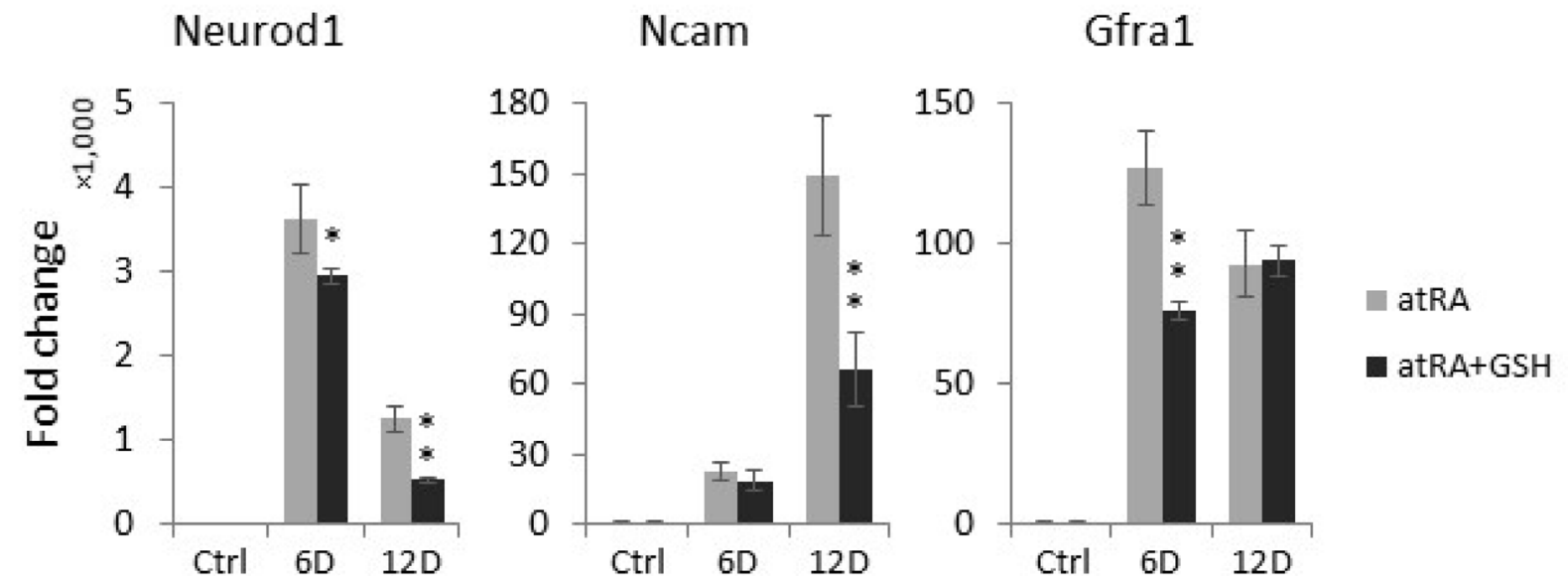

Figure 6: The antioxidant GSH suppresses the expression of neuronal markers induced by paraquat (PQ). (A) NT2 cells treated as indicated were collected for total RNA extraction. The expression of neuronal markers was measured by qPCR. (B) Cells were treated with atRA (RA) or co-treated with GSH for indicated days (D). The expression of neuronal markers was measured by qPCR. Bar: mean $\pm \mathrm{SD} ;{ }^{*} p<0.05,{ }^{* *} p<0.01$. 
A
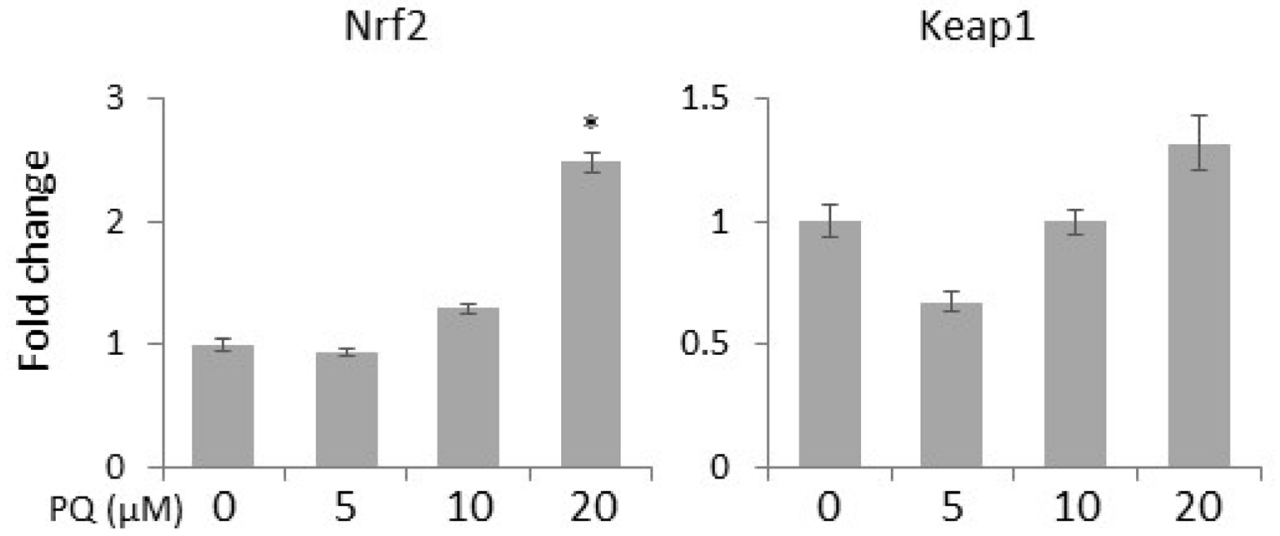

B

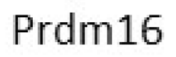

Prdm16
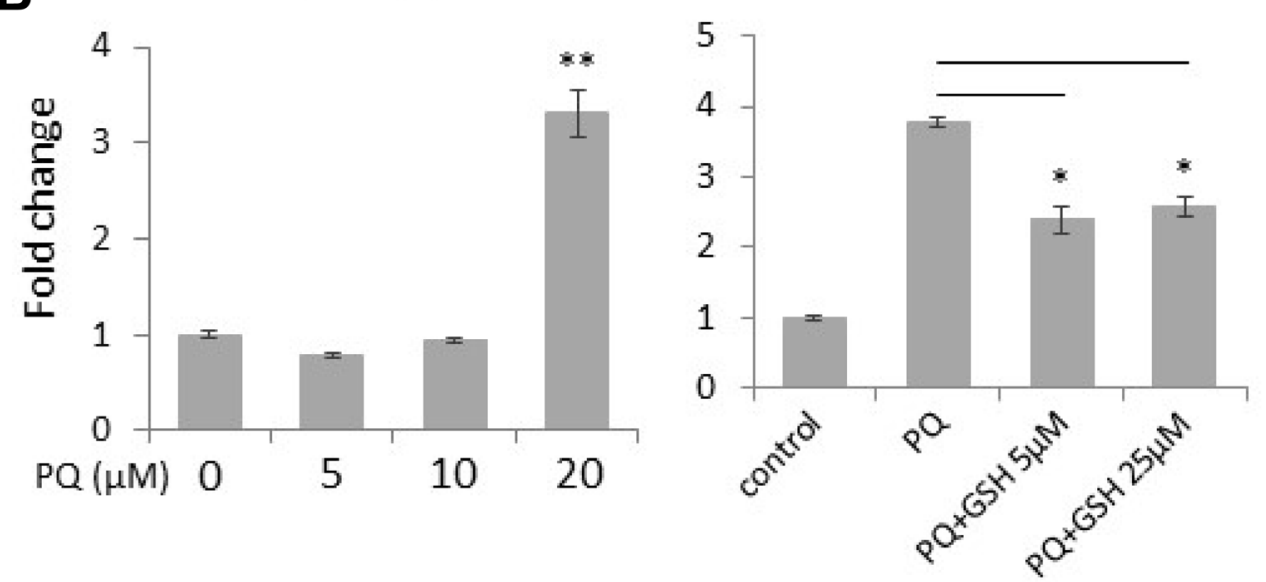

C

Nestin

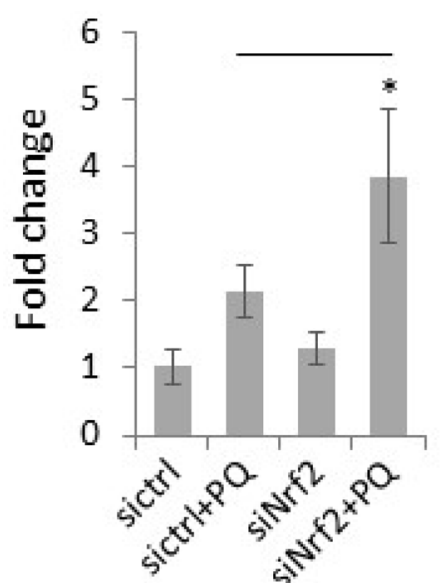

Gfra1

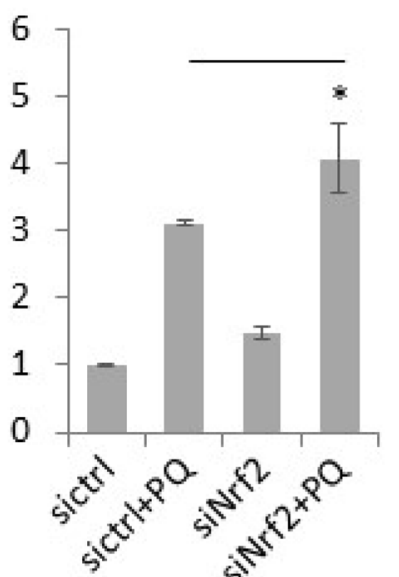

Hoxa1

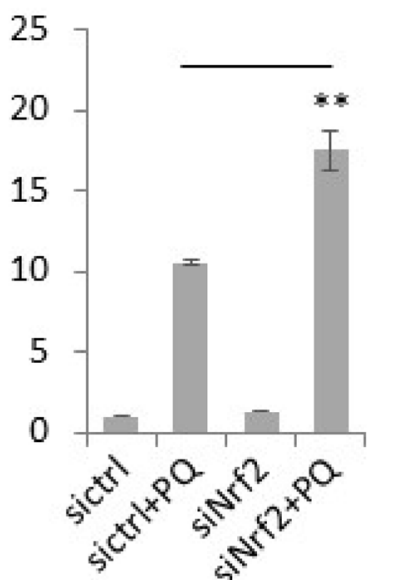

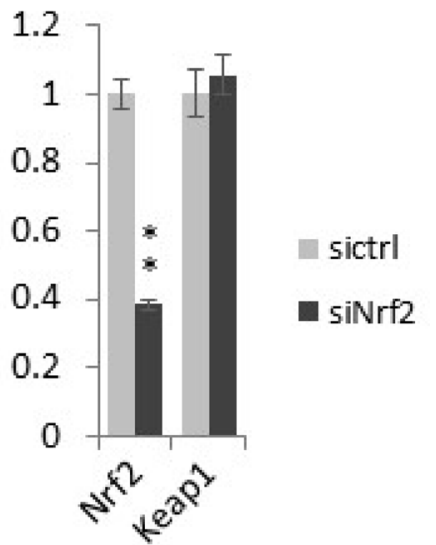

Figure 7: Antioxidant signaling is activated by ROS and is involved in neuronal gene expression in NT2 cells. (A) Cells were treated with the increasing concentrations of paraquat (PQ) for two days. The expression of the key redox signaling genes, $N r f 2$ and Keap1, was measured by qPCR. (B) Cells were treated with paraquat alone (left panel) or co-treated with paraquat and GSH (right panel). The expression of the antioxidant Prdm16 mRNA level was examined by qPCR. (C) Cells were transfected with siRNA targeting Nrf2 (siNrf2) and then treated with paraquat for two days. The expression of neural progenitor marker (Nestin) and neuronal markers (Grfal and Hoxal) was monitored by qPCR. Bar: mean $\pm \mathrm{SD} ;{ }^{*} p<0.05,{ }^{* *} p<0.01$. 
program in NT2 cells. This observation resonates with a recent study that reported the effect of another antioxidant, $\mathrm{N}$-acetyl cysteine (NAC), on neuronal differentiation in human adipose tissue-derived multipotent adult stem cells [18]. Hence, it certainly warrants future studies to characterize the relationship between redox and atRA signaling in the context of neurogenesis. In addition, we found that phospho-ERK1/2 levels are increased upon
A

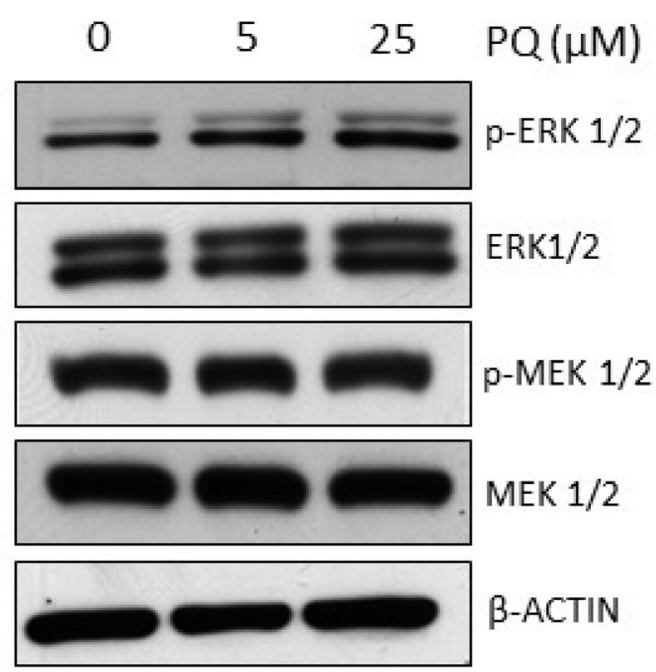

C
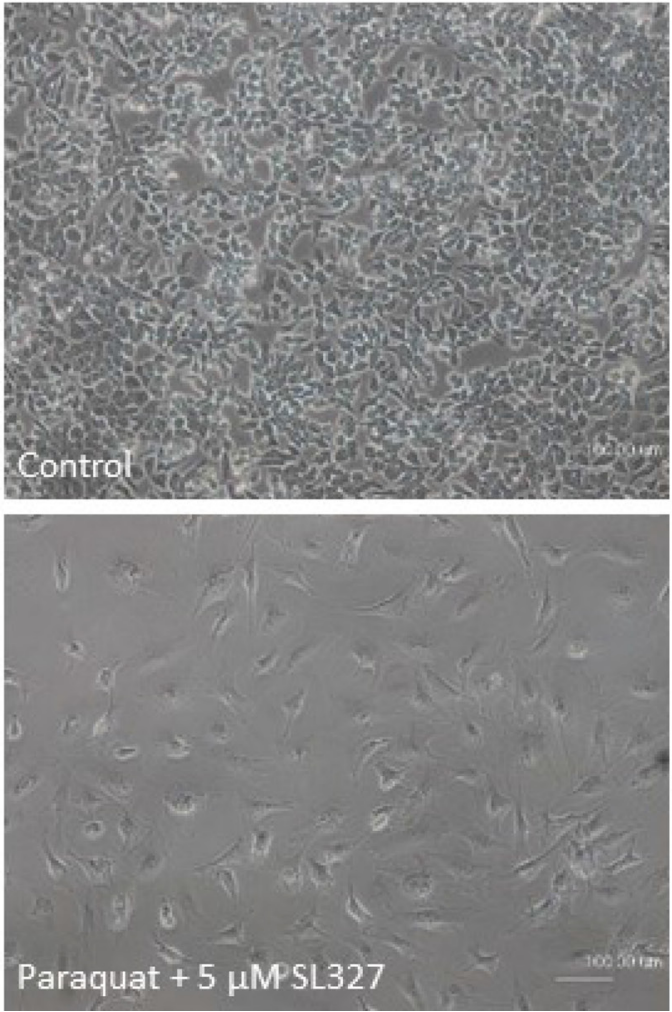

B

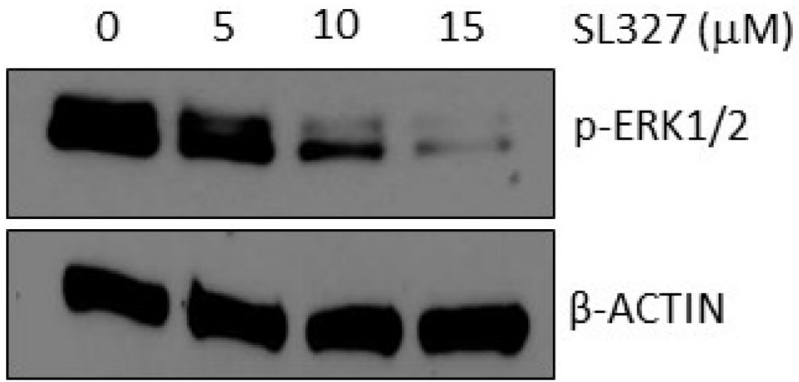

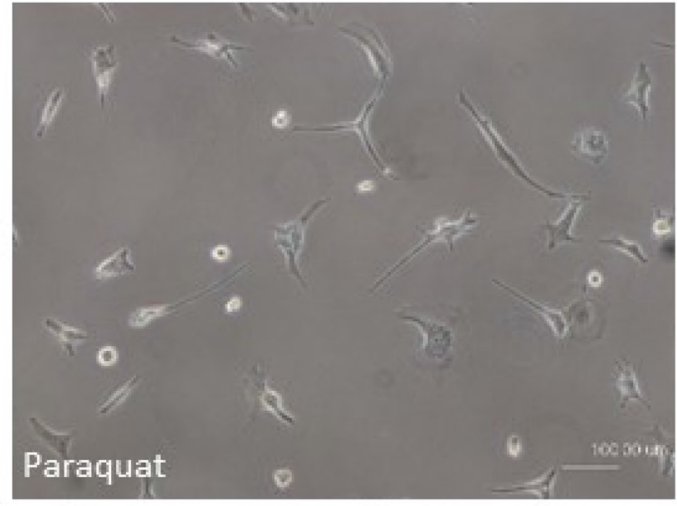

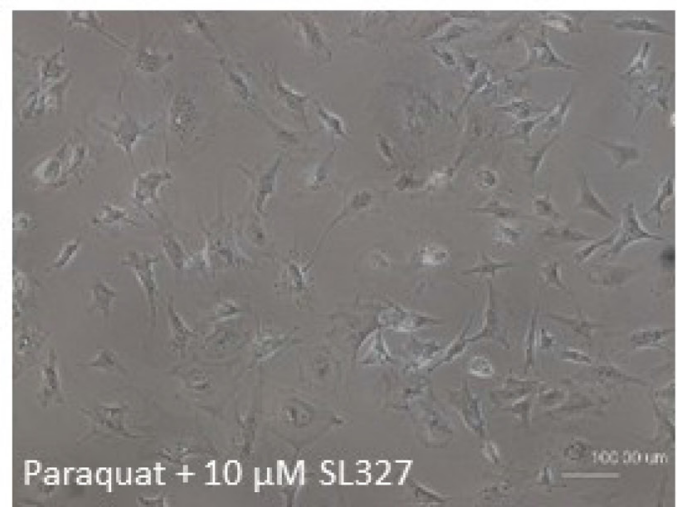

Figure 8: MAPK-ERK1/2 signaling is activated by high ROS in NT2 cells. (A) Cells were treated with the increasing concentrations of paraquat (PQ). The activation status of ERK1/2 and the upstream MEK1/2 was determined by immunoblotting with indicated antibodies. $\beta$-ACTIN was used as the loading control. (B) Cells were treated with indicated doses of MEK1/2 inhibitor, SL327. The efficacy of the inhibitor was demonstrated by immunoblotting for phospho-ERK1/2. (C) Cells were concurrently treated with 100 $\mu \mathrm{M}$ paraquat and indicated doses of SL327 for 6 days. The phase contrast images showed the cell density and morphology under different treatments. Scale bar: $100 \mu \mathrm{m}$. 
paraquat-induced oxidative stress in NT2 cells (Figure 8A). Interestingly, the activation status of MEK1/2, an ERK1/2 upstream kinase, was not affected by paraquat treatment, suggesting that ROS signaling may function the downstream of MEK1/2. Nonetheless, as ERK1/2 has been demonstrated to promote neuronal differentiation in murine ESCs [43], our observation supports the finding that oxidative stress facilitates a neuronal fate selection in stem cells. It will be intriguing to further investigate the dynamic crosstalk between redox signaling, MAPKERK1/2 signaling and retinoic acid signaling. This will provide us novel and exciting insights into how to promote the exit from stem cell state and to enhance neuronal differentiation in response to various stimuli. This is of particular significance given that many neurodegenerative diseases, including Alzheimer's disease, Parkinson's and Huntington's disease, are characterized by the loss of neurons in the central nervous system. Hence, a comprehensive understanding of the role of ROS in regulating stem cell fate selection may ultimately lead to innovative approaches of generating functional neurons from stem cells to alleviate neurodegeneration.

Besides the nervous system, an accumulation of ROS is closely associated with pathophysiological mechanisms underlying cancer and metastasis [45-49]. Unlike tumour cells, cancer stem cells (CSCs) maintain a low ROS level, although the underlying mechanism remains to be addressed. Many lines of evidence have suggested that CSCs are one of the primary causes for drug resistance and tumour recurrence [50]. Since CSCs have been found to share some basic properties with normal stem cells, including self-renewal and multipotent differentiation capacity, our study on the role of ROS in regulating hEC cell behaviour may also shed light onto some interesting questions, such as how to manipulate ROS level and/or antioxidant machinery in CSCs to induce cell death and to prevent tumour relapse. Indeed, some of oxidizing agents such as niclosamide have been shown to selectively eliminate CSCs of acute and chronic myeloid leukemia [50-53], suggesting that the induction of oxidative stress may cause CSCs to lose stemness, leading to an improved long-term therapeutic outcome.

In summary, future work is urgently needed to elucidate the redox regulatory mechanisms in hESCs which may ultimately lead to new strategies of producing functional neurons to treat neurodegenerative diseases and could be even applied to manipulate the fate of CSCs to improve relapse-free survival.

\section{CONCLUSIONS}

In this study, we successfully induced the oxidative stress in the human EC line NT2 by treating paraquat at various concentrations. We showed that in the treated cells, stemness-related gene expression was downregulated but the expression of neuronal markers was conversely upregulated. Importantly, increased neuronal marker expression in treated NT2 cells was accompanied by a morphological change, which is reminiscent of the neurite outgrowth. Interestingly, the addition of the antioxidant agent GSH reversed the expression of neuronal genes induced by either oxidative stress or atRA. This suggests that atRA-mediated neuronal differentiation also involves redox signaling and that antioxidant activity is required for stem cells to maintain their stem identity. Lastly, we found that oxidative stress activates MAPK-ERK1/2, suggesting a functional crosstalk between oxidative stress signaling and MAPK signaling in the aspect of neurogenesis program in NT2 cells.

\section{MATERIALS AND METHODS}

\section{Culture of NT2 cells}

NT2 cell line was purchased from ATCC (CRL1973). The cells were maintained in DMEM-GlutaMax ${ }^{\mathrm{TM}}$ (\#10569010, ThermoFisher Scientific) supplemented with $10 \%$ FBS (Hyclone). To induce oxidative stress, the cells were treated with the various concentrations of paraquat (Sigma-Aldrich) or $\mathrm{H}_{2} \mathrm{O}_{2}$ (Sigma-Aldrich) for indicated time periods. The cells were then subjected to various assays. To induce neuronal differentiation, NT2 cells were also treated with $10 \mu \mathrm{M}$ all-trans retinoic acid (atRA) (Sigma-Aldrich) for indicated time periods. To investigate the effect of antioxidant on neuronal gene expression, oxidized cells were treated with $50 \mu \mathrm{M}$ glutathione (GSH) (Sigma-Aldrich) for two days. NT2 cells were treated with SL327 (Sigma-Aldrich) to examine the effect of inhibiting MEK1/2 on paraquat-induced neuronal differentiation of the cells. Cells were treated with SL327 at various concentrations for 24 hours (Western blot analysis) and 6 days (phase contrast images), respectively.

NT2 cells seeded in 6-well plates were transfected with Lipofectamine 3000 (Invitrogen) as instructed. The siRNA pool targeting human NRF2 was purchased from Sigma-Aldrich (MISSION ${ }^{\circledR}$ esiRNAs \#EHU093471).

\section{Measurement of ROS levels in NT2 cells}

NT2 cells were cultured in 6-well plates up to $80 \%$ confluency and treated with $0 \mu \mathrm{M}, 5 \mu \mathrm{M}$ and $25 \mu \mathrm{M}$ of paraquat. Cells were then harvested after 24 and 40 hours, and stained with $10 \mu \mathrm{M}$ chloromethyl-H2DCFDA dye (\#C6827, ThermoFisher Scientific) for 30 minutes at $37^{\circ} \mathrm{C}$. Intensity of the dye that can reflect ROS levels in the cells was measured using SpectraMax M5 and DAKO CyAn ADP Flow Cytometer, respectively. Statistical analysis was performed on GraphPad Prism 6.0 software. All values were expressed in mean \pm standard error of mean. Using unpaired $t$-test, data was analysed and $p<$ 0.05 was considered statistically significant. 


\section{Immunocytochemistry}

NT2 cells were cultured on $13 \mathrm{~mm}$ cover slips up to $80 \%$ confluency, and then treated with $0 \mu \mathrm{M}$ and 50 $\mu \mathrm{M}$ of paraquat. Following the treatment, the cells were fixed in $4 \%$ paraformaldehyde and permeabilized using $0.2 \%$ Triton X-100 in $1 \mathrm{X}$ PBS. The cells were blocked in $1 \%(\mathrm{w} / \mathrm{v}) \mathrm{BSA}$ in $1 \mathrm{X}$ PBS and stained for overnight at $4^{\circ} \mathrm{C}$ with the following primary antibodies: OCT4 (1:400, \#2750, Cell Signaling Technology; CST), NANOG(1:200, \#3580, CST), TDGF1(1:200, \#2020, CST), $\beta 3$-tubulin (1:200, \#4466, CST), and NeuroD1 (1:100, \#4373, CST). The cells were subsequently stained with the following secondary antibodies: DyLight 488-AffiniPure Rabbit Anti-Mouse IgG (H+L) (1:200, Jackson ImmunoResearch Laboratories) and Goat Anti-Rabbit IgG $(\mathrm{H}+\mathrm{L})$ Alexa Fluor 488 Conjugate (1:200, \#A11008, ThermoFisher Scientific). To measure ROS activity (superoxide level), NT2 cells were stained with $30 \mu \mathrm{M}$ dihydroethidium (DHE) (\#D1168, ThermoFisher Scientific) for 5 minutes. Slides were mounted using Vectashield mounting medium containing DAPI on a glass slide and viewed under the confocal microscope (Olympus Fluoview FV1000 cLSM).

\section{Protein extraction and Western blot analysis}

NT2 cells were cultured up to $80 \%$ confluency and treated with $0 \mu \mathrm{M}, 50 \mu \mathrm{M}, 75 \mu \mathrm{M}$ and $100 \mu \mathrm{M}$ of paraquat for 40 hours. Protein was extracted using M-PER ${ }^{\mathrm{TM}}$ Mammalian Protein Extraction Reagent (\#78501, ThermoFisher Scientific) supplemented with Halt ${ }^{\mathrm{TM}}$ Protease Inhibitor Cocktail and EDTA (\#87786, ThermoFisher Scientific). $30 \mu \mathrm{g}$ of protein lysate was resolved on $8 \%$ SDS-PAGE gels, transferred onto nitrocellulose membrane (Bio-Rad) and then blocked using $5 \%(\mathrm{w} / \mathrm{v})$ BSA or milk in $1 \mathrm{X}$ TBST. The membrane was then probed overnight at $4{ }^{\circ} \mathrm{C}$ with the respective primary antibodies: NANOG $(1: 1000, \# 3580, \mathrm{CST})$, OCT4 (1:1000, \#2750, CST), TDGF1 (1:1000, \#2020, CST), ERK1/2 (1:1000, \#9102, CST), phospho-ERK1/2 (1:1000, \#9101, CST), p38 (1:1000, \#Ab7952, Abcam), phospho-p38 (1:1000, \#9211, CST), JNK1/2 (1:1000, \#9252, Sigma-Aldrich), phospho-JNK1/2 (1:1000, \#4668, CST), MEK1/2 (1:1000, \#4694, CST), phospho-MEK1/2 $(1: 1000, \# 9154, \mathrm{CST})$ and $\beta$-actin $(1: 10000, \# \mathrm{~A} 2228$, Sigma-Aldrich). The membrane was subsequently washed in $1 \mathrm{X}$ TBST and probed with the following secondary antibodies for two hours: Pierce Goat Anti-Mouse IgG $(\mathrm{H}+\mathrm{L})$ Peroxidase Conjugated $(1: 6000 ; 1: 10000$ for $\beta$-actin, \#31430, Thermo Scientific) and Pierce Goat Anti-Rabbit IgG $(\mathrm{H}+\mathrm{L})$ Peroxidase Conjugated (1:6000, \#31460, Thermo Scientific). Clarity ${ }^{\mathrm{TM}}$ ECL Western Blotting Substrate (Bio-Rad) was used for detection, and the X-ray films were developed using Konica Minolta SRX-101A developer.

\section{RNA extraction and quantitative reverse transcription PCR}

NT2 cells treated with either paraquat, GSH or atRA were lysed in Trizol ${ }^{\mathrm{TM}}$ (Invitrogen). The extracted total RNA was quantified by NanoDrop1000. $2 \mu \mathrm{g}$ of total RNA were treated with the TurboDNase (Ambion) to eliminate residual genomic DNA. The RNA sample was then reverse transcribed into cDNA by using the GoScript Reverse Transcription kit (Promega). The resultant cDNA was used as a template for qPCR on the Fast platform (Applied Biosystems). The relative abundance of gene transcripts was quantified by the $-\Delta \Delta \mathrm{Ct}$ method. The statistical significance was determined by the Student $t$-test. The primers used for qPCR were as follows: Cyp26a1 forward primer 5'-gcaggaaatacggettcatctac-3' and reverse primer 5'-aggagtcgtgcaggttagagagg-3'; Gfral forward primer $5^{\prime}$-ctgaagcagaagtcgctctacaac- $3^{\prime}$ and reverse primer 5'-ggaccacccggaatatatctgac-3'; Hoxal forward primer 5'-ac ttcactaccaagcagctcacg- $3^{\prime}$ and reverse primer $5^{\prime}$-cgaaga gctggacttctctgagg-3'; Keapl forward primer 5'-tcatccag ccctgtcttcaagg- $3^{\prime}$ and reverse primer $5^{\prime}$-acatgacagca ccgttcatgac- $3^{\prime}$; Ncam forward primer $5^{\prime}$-acatcttcagcgac gatagttcc- $3^{\prime}$ and reverse primer $5^{\prime}$-ctaattccatggcagtctgg ttc-3'; Nestin forward primer $5^{\prime}$-atctctgggagcatggaacctg- $3^{\prime}$ and reverse primer $5^{\prime}$-tcttcccacctctgcacatctg-3'; Neurod 1 forward primer $5^{\prime}$-ctgtccaaaatcgagactctgc- $3^{\prime}$ and reverse primer $5^{\prime}$-tctgctcaggcagaaaagtcc- $3^{\prime} ; \mathrm{Nrf} 2$ forward primer $5^{\prime}$-ccagcacatccagtcagaaacc-3' and reverse primer $5^{\prime}$-agca atgaagactgggetctc-3'; Pax6 forward primer $5^{\prime}$-tcagcac cagtgtctaccaacc-3' and reverse primer $5^{\prime}$-atgcaggagtatg aggaggtctg-3'; Prdm 16 forward primer $5^{\prime}$-accatgtgtcagat cagtgagc- $3^{\prime}$ and reverse primer $5^{\prime}$-aagagttcgtcacactcg tcac- $3^{\prime}$.

\section{Author contributions}

H.Q. and B.G.H initiated the project and designed the experiments. H.Q., S.S.C., L.Z.T., Z.S.L.H performed experiments on neuronal differentiation and antioxidant pathway. P.K., S.E.W., W.S.T performed experiments on ROS induction, stemness status and MAPK activation. H.Q. and B.G.H. wrote the manuscript.

\section{CONFLICTS OF INTEREST}

The authors declare no conflicts of interest.

\section{FUNDING}

The study was supported by the NUS start-up fund to H.Q. (R-181-000-155-133), MOE TIER1 to H.Q. (R181-000-163-112) and MOE TIER1 to B.G.H (R-181-000172-112). 


\section{REFERENCES}

1. Vogt MT, Thomas C, Vassallo CL, Basford RE, Gee JB. Glutathione-dependent peroxidative metabolism in the alveolar macrophage. J Clin Invest. 1971; 50:401-10. https://doi.org/10.1172/JCI106507.

2. Briggs RT, Drath DB, Karnovsky ML, Karnovsky MJ. Localization of NADH oxidase on the surface of human polymorphonuclear leukocytes by a new cytochemical method. J Cell Biol. 1975; 67:566-86.

3. Babcock GT, Wikström M. Oxygen activation and the conservation of energy in cell respiration. Nature. 1992; 356:301-9. https://doi.org/10.1038/356301a0.

4. Margittai E, Bánhegyi G. Oxidative folding in the endoplasmic reticulum: towards a multiple oxidant hypothesis? FEBS Lett. 2010; 584:2995-8. https://doi. org/10.1016/j.febslet.2010.05.055.

5. Trachootham D, Alexandre J, Huang P. Targeting cancer cells by ROS-mediated mechanisms: a radical therapeutic approach? Nat Rev Drug Discov. 2009; 8:579-91. https:// doi.org/10.1038/nrd2803.

6. Finkel T. Radical medicine: treating ageing to cure disease. Nat Rev Mol Cell Biol. 2005; 6:971-6. https://doi. org/10.1038/nrm1763.

7. Ueno S, Yasutake K, Tohyama D, Fujimori T, Ayusawa D, Fujii M. Systematic screen for genes involved in the regulation of oxidative stress in the nematode Caenorhabditis elegans. Biochem Biophys Res Commun. 2012; 420:552-7. https://doi.org/10.1016/j. bbrc.2012.03.032.

8. Liu Y, Kern JT, Walker JR, Johnson JA, Schultz PG, Luesch H. A genomic screen for activators of the antioxidant response element. Proc Natl Acad Sci USA. 2007; 104:5205-10. https://doi.org/10.1073/pnas.0700898104.

9. Itoh K, Wakabayashi N, Katoh Y, Ishii T, Igarashi K, Engel JD, Yamamoto M. Keap1 represses nuclear activation of antioxidant responsive elements by Nrf2 through binding to the amino-terminal Neh2 domain. Genes Dev. 1999; 13:76-86.

10. Nguyen T, Sherratt PJ, Huang HC, Yang CS, Pickett CB. Increased protein stability as a mechanism that enhances Nrf2-mediated transcriptional activation of the antioxidant response element. Degradation of $\mathrm{Nrf} 2$ by the $26 \mathrm{~S}$ proteasome. J Biol Chem. 2003; 278:4536-41. https://doi. org/10.1074/jbc.M207293200.

11. Osburn WO, Kensler TW. Nrf2 signaling: an adaptive response pathway for protection against environmental toxic insults. Mutat Res. 2008; 659:31-9. https://doi. org/10.1016/j.mrrev.2007.11.006.

12. Shi X, Zhang Y, Zheng J, Pan J. Reactive oxygen species in cancer stem cells. Antioxid Redox Signal. 2012; 16:121528. https://doi.org/10.1089/ars.2012.4529.
13. Bigarella CL, Liang R, Ghaffari S. Stem cells and the impact of ROS signaling. Development. 2014; 141:420618. https://doi.org/10.1242/dev.107086.

14. Liang R, Ghaffari S. Stem cells, redox signaling, and stem cell aging. Antioxid Redox Signal. 2014; 20:1902-16. https://doi.org/10.1089/ars.2013.5300.

15. Holmström KM, Finkel T. Cellular mechanisms and physiological consequences of redox-dependent signaling. Nat Rev Mol Cell Biol. 2014; 15:411-21. https://doi. org/10.1038/nrm3801.

16. Jang YY, Sharkis SJ. A low level of reactive oxygen species selects for primitive hematopoietic stem cells that may reside in the low-oxygenic niche. Blood. 2007; 110:305663. https://doi.org/10.1182/blood-2007-05-087759.

17. Naka K, Muraguchi T, Hoshii T, Hirao A. Regulation of reactive oxygen species and genomic stability in hematopoietic stem cells. Antioxid Redox Signal. 2008; 10:1883-94. https://doi.org/10.1089/ars.2008.2114.

18. Domenis R, Bergamin N, Gianfranceschi G, Vascotto C, Romanello M, Rigo S, Vagnarelli G, Faggiani M, Parodi P, Kelley MR, Beltrami CA, Cesselli D, Tell G, et al. The redox function of APE1 is involved in the differentiation process of stem cells toward a neuronal cell fate. PLoS One. 2014; 9:e89232. https://doi.org/ 10.1371/journal.pone.0089232.

19. Forsyth NR, Musio A, Vezzoni P, Simpson AH, Noble BS, McWhir J. Physiologic oxygen enhances human embryonic stem cell clonal recovery and reduces chromosomal abnormalities. Cloning Stem Cells. 2006; 8:16-23. https:// doi.org/10.1089/clo.2006.8.16.

20. Guo YL, Chakraborty S, Rajan SS, Wang R, Huang F. Effects of oxidative stress on mouse embryonic stem cell proliferation, apoptosis, senescence, and self-renewal. Stem Cells Dev. 2010; 19:1321-31. https://doi.org/10.1089/ scd.2009.0313.

21. Schwartz CM, Spivak CE, Baker SC, McDaniel TK, Loring JF, Nguyen C, Chrest FJ, Wersto R, Arenas E, Zeng X, Freed WJ, Rao MS. NTera2: a model system to study dopaminergic differentiation of human embryonic stem cells. Stem Cells Dev. 2005; 14:517-34. https://doi. org/10.1089/scd.2005.14.517.

22. Watanabe K, Meyer MJ, Strizzi L, Lee JM, Gonzales M, Bianco C, Nagaoka T, Farid SS, Margaryan N, Hendrix MJ, Vonderhaar BK, Salomon DS. Cripto-1 is a cell surface marker for a tumorigenic, undifferentiated subpopulation in human embryonal carcinoma cells. Stem Cells. 2010; 28:1303-14. https://doi.org/10.1002/stem.463.

23. Houldsworth J, Heath SC, Bosl GJ, Studer L, Chaganti RS. Expression profiling of lineage differentiation in pluripotential human embryonal carcinoma cells. Cell Growth Differ. 2002; 13:257-64. 
24. Hu Q, Tanasa B, Trabucchi M, Li W, Zhang J, Ohgi KA, Rose DW, Glass CK, Rosenfeld MG. DICER- and AGO3dependent generation of retinoic acid-induced DR2 Alu RNAs regulates human stem cell proliferation. Nat Struct Mol Biol. 2012; 19:1168-75. https://doi.org/10.1038/ nsmb. 2400 .

25. Thakurela S, Tiwari N, Schick S, Garding A, Ivanek R, Berninger B, Tiwari VK. Mapping gene regulatory circuitry of Pax6 during neurogenesis. Cell Discov. 2016; 2:15045. https://doi.org/10.1038/celldisc.2015.45.

26. Yoong LF, Wan G, Too HP. GDNF-induced cell signaling and neurite outgrowths are differentially mediated by GFRalpha1 isoforms. Mol Cell Neurosci. 2009; 41:464-73. https://doi.org/10.1016/j.mcn.2009.05.002.

27. Martinez-Ceballos E, Gudas LJ. Hoxa1 is required for the retinoic acid-induced differentiation of embryonic stem cells into neurons. J Neurosci Res. 2008; 86:2809-19. https://doi.org/10.1002/jnr.21729.

28. Cunningham BA, Hemperly JJ, Murray BA, Prediger EA, Brackenbury R, Edelman GM. Neural cell adhesion molecule: structure, immunoglobulin-like domains, cell surface modulation, and alternative RNA splicing. Science. 1987; 236:799-806.

29. Gaudillière B, Konishi Y, de la Iglesia N, Yao GL, Bonni A. A CaMKII-NeuroD signaling pathway specifies dendritic morphogenesis. Neuron. 2004; 41:229-41.

30. Chithalen JV, Luu L, Petkovich M, Jones G. HPLC-MS/MS analysis of the products generated from all-trans-retinoic acid using recombinant human CYP26A. J Lipid Res. 2002; 43:1133-42.

31. Pennimpede T, Cameron DA, MacLean GA, Li H, AbuAbed S, Petkovich M. The role of CYP26 enzymes in defining appropriate retinoic acid exposure during embryogenesis. Birth Defects Res A Clin Mol Teratol. 2010; 88:883-94. https://doi.org/10.1002/bdra.20709.

32. Sestan N, Artavanis-Tsakonas S, Rakic P. Contactdependent inhibition of cortical neurite growth mediated by notch signaling. Science. 1999; 286:741-6.

33. Tischfield MA, Baris $\mathrm{HN}$, Wu C, Rudolph G, Van Maldergem L, He W, Chan WM, Andrews C, Demer JL, Robertson RL, Mackey DA, Ruddle JB, Bird TD, et al. Human TUBB3 mutations perturb microtubule dynamics, kinesin interactions, and axon guidance. Cell. 2010; 140:74-87. https://doi.org/10.1016/j.cell.2009.12.011.

34. Chuikov S, Levi BP, Smith ML, Morrison SJ. Prdm16 promotes stem cell maintenance in multiple tissues, partly by regulating oxidative stress. Nat Cell Biol. 2010; 12:9991006. https://doi.org/10.1038/ncb2101.

35. Cui XY, Hu QD, Tekaya M, Shimoda Y, Ang BT, Nie DY, Sun L, Hu WP, Karsak M, Duka T, Takeda Y, Ou LY, Dawe GS, et al. NB-3/Notch1 pathway via Deltex1 promotes neural progenitor cell differentiation into oligodendrocytes. J Biol Chem. 2004; 279:25858-65. https://doi.org/10.1074/ jbc.M313505200.
36. von Bohlen Und Halbach O. Immunohistological markers for staging neurogenesis in adult hippocampus. Cell Tissue Res. 2007; 329:409-20. https://doi.org/10.1007/ s00441-007-0432-4.

37. Kyriakis JM, Avruch J. Mammalian MAPK signal transduction pathways activated by stress and inflammation: a 10-year update. Physiol Rev. 2012; 92:689-737. https:// doi.org/10.1152/physrev.00028.2011.

38. Yang SR, Kim SJ, Byun KH, Hutchinson B, Lee BH, Michikawa M, Lee YS, Kang KS. NPC1 gene deficiency leads to lack of neural stem cell self-renewal and abnormal differentiation through activation of $\mathrm{p} 38$ mitogen-activated protein kinase signaling. Stem Cells. 2006; 24:292-8. https://doi.org/10.1634/stemcells.2005-0221.

39. Gakhar-Koppole N, Hundeshagen P, Mandl C, Weyer SW, Allinquant B, Müller U, Ciccolini F. Activity requires soluble amyloid precursor protein alpha to promote neurite outgrowth in neural stem cell-derived neurons via activation of the MAPK pathway. Eur J Neurosci. 2008; 28:871-82. https://doi. org/10.1111/j.1460-9568.2008.06398.x.

40. Sato K, Hamanoue M, Takamatsu K. Inhibitors of p38 mitogen-activated protein kinase enhance proliferation of mouse neural stem cells. J Neurosci Res. 2008; 86:2179-89. https://doi.org/10.1002/jnr.21668.

41. Ma DK, Ponnusamy K, Song MR, Ming GL, Song H. Molecular genetic analysis of FGFR1 signalling reveals distinct roles of MAPK and PLCgammal activation for self-renewal of adult neural stem cells. Mol Brain. 2009; 2:16. https://doi.org/10.1186/1756-6606-2-16.

42. Kim SY, Han YM, Oh M, Kim WK, Oh KJ, Lee SC, Bae $\mathrm{KH}$, Han BS. DUSP4 regulates neuronal differentiation and calcium homeostasis by modulating ERK1/2 phosphorylation. Stem Cells Dev. 2015; 24:686-700. https://doi.org/10.1089/scd.2014.0434.

43. Li Z, Theus MH, Wei L. Role of ERK $1 / 2$ signaling in neuronal differentiation of cultured embryonic stem cells. Dev Growth Differ. 2006; 48:513-23. https://doi. org/10.1111/j.1440-169X.2006.00889.x.

44. Longoni R, Spina L, Vinci S, Acquas E. The MEK inhibitor SL327 blocks acquisition but not expression of lithiuminduced conditioned place aversion: a behavioral and immunohistochemical study. Psychopharmacology (Berl). 2011; 216:63-73. https://doi.org/10.1007/s00213-0112192-9.

45. Slaga TJ, Klein-Szanto AJ, Triplett LL, Yotti LP, Trosko KE. Skin tumor-promoting activity of benzoyl peroxide, a widely used free radical-generating compound. Science. 1981; 213:1023-5.

46. Weitzman SA, Weitberg AB, Stossel TP, Schwartz J, Shklar G. Effects of hydrogen peroxide on oral carcinogenesis in hamsters. J Periodontol. 1986; 57:685-8. https:/doi. org/10.1902/jop.1986.57.11.685. 
47. Stich HF, Anders F. The involvement of reactive oxygen species in oral cancers of betel quid/tobacco chewers. Mutat Res. 1989; 214:47-61.

48. Kang DH. Oxidative stress, DNA damage, and breast cancer. AACN Clin Issues. 2002; 13:540-9.

49. Ríos-Arrabal S, Artacho-Cordón F, León J, RománMarinetto E, Del Mar Salinas-Asensio M, Calvente I, Núñez MI. Involvement of free radicals in breast cancer. Springerplus. 2013; 2:404. https://doi.org/10.1186/21931801-2-404.

50. Ogasawara MA, Zhang H. Redox Regulation and Its Emerging Roles in Stem Cells and Stem-Like Cancer Cells. Antioxid Redox Signal. 2009; 11:1107-22. https://doi. org/10.1089/ars.2008.2308.

51. Guzman ML, Rossi RM, Karnischky L, Li X, Peterson DR, Howard DS, Jordan CT. The sesquiterpene lactone parthenolide induces apoptosis of human acute myelogenous leukemia stem and progenitor cells. Blood. 2005; 105:4163-9. https://doi.org/10.1182/blood-200410-4135.

52. Ito K, Bernardi R, Morotti A, Matsuoka S, Saglio G, Ikeda Y, Rosenblatt J, Avigan DE, Teruya-Feldstein J, Pandolfi PP. PML targeting eradicates quiescent leukaemia-initiating cells. Nature. 2008; 453:1072-8. https://doi.org/10.1038/ nature 07016.

53. Jin Y, Lu Z, Ding K, Li J, Du X, Chen C, Sun X, Wu Y, Zhou J, Pan J. Antineoplastic mechanisms of niclosamide in acute myelogenous leukemia stem cells: inactivation of the NF-kappaB pathway and generation of reactive oxygen species. Cancer Res. 2010; 70:2516-27. https://doi. org/10.1158/0008-5472.CAN-09-3950. 